\title{
3 \\ Hard Carbon for Na-ion Batteries: From Synthesis to Performance and Storage Mechanism
}

\author{
Carolina DEL MAR SAAVEDRA RIOS ${ }^{1}$, Adrian BEDA ${ }^{2,3}$ \\ Loic SIMONIN ${ }^{1}$ and Camélia MATEI GHIMBEU ${ }^{2,3,4}$ \\ ${ }^{1}$ Université Grenoble Alpes, CEA, LITEN, DEHT, LM, Grenoble, France \\ ${ }^{2}$ Université de Haute-Alsace, CNRS, Institut de Science des Matériaux de Mulhouse (IS2M) UMR 7361, Mulhouse, France \\ ${ }^{3}$ University of Strasbourg, Strasbourg, France \\ ${ }^{4}$ Réseau sur le Stockage Electrochimique de l'Energie (RS2E), FR CNRS 3459, Amiens, France
}

\subsection{Introduction}

The development of Na-ion batteries (NIBs) is currently regarded as a sustainable, cheaper and long-lasting technology (Table 3.1) compared to that of Li-ion batteries (LIBs). The design of suitable anode materials that exhibit high performance is still a key challenge in order to commercialize NIBs. Carbonaceous materials, titanium-based compounds, metalbased alloys, chalcogen materials and organic compounds (Wang et al. 2017) were explored until now as possible anodes. Unfortunately, there are still several limitations for each of these materials, mainly concerning a low initial Coulombic Efficiency (ICE), a limited cycle life, poor rate performance and a large volume expansion. In addition, an important lack of comprehension of the sodium storage mechanisms into these materials limits their practical utilization (Wang et al. 2017).

Although LIBs and NIBs present similar components and similar electrochemical working principle, graphite, the most common anode material used in commercial LIBs, proves to exhibit poor electrochemical performance when used in NIBs (capacity $\sim 30 \mathrm{mAh} \cdot \mathrm{g}^{-1}$ ) (Stevens and Dahn 2001). This is related to several factors such as the weaker binding energy of $\mathrm{Na}$ with the graphite making the reversible intercalation difficult, the larger ionic radius of $\mathrm{Na}(1.02 \AA)$ compared to that of $\mathrm{Li}(0.76 \AA)$, as well as the tendency of Na to coordinate in octahedral or prismatic sites leading thus to the impossibility of $\mathrm{Na}$ ions to form stable intercalation compounds in carbonate-based electrolytes (Liu et al. 2016). The higher standard redox potential of $\mathrm{Na}(-2.71 \mathrm{~V}$ vs. SHE) than $\mathrm{Li}(-3.04 \mathrm{~V}$ versus $\mathrm{SHE})$ and the larger atomic weight of sodium represent other issues when considering NIBs as they trigger a lower energy density and larger electrode weight.

Table 3.1. Comparison between sodium and lithium characteristics

\begin{tabular}{cccccc}
\hline Element & $\begin{array}{c}\text { Abundance } \\
(\mathbf{p p m})\end{array}$ & $\begin{array}{c}\text { Carbonate cost } \\
(\mathbf{U S D} / \mathbf{t})\end{array}$ & $\begin{array}{c}\text { Ionic radius } \\
(\mathbf{\AA})\end{array}$ & $\begin{array}{c}\text { Current } \\
\text { collector }\end{array}$ & $\begin{array}{c}\text { Voltage vs SHE } \\
(\mathbf{V})\end{array}$ \\
\hline $\mathrm{Li}$ & 20 & 6000 & 0.76 & $\mathrm{Cu}$ & -3.04 \\
$\mathrm{Na}$ & 23000 & 200 & 1.02 & $\mathrm{Al}$ & -2.71 \\
\hline
\end{tabular}


Among the different carbon-based anode possibilities, hard carbons are especially interesting owing to their high precursor availability, low price, reasonable capacity (can reach $\left.\sim 300 \mathrm{mAh}^{\cdot} \mathrm{g}^{-1}\right)$ and low operating voltage $\left(\sim 0 \mathrm{~V}\right.$ vs. $\left.\mathrm{Na}^{+} / \mathrm{Na}\right)$, which make them safer. Despite the positive aspects listed above, NIBs using hard carbon materials are still far from large-scale commercialization due to the relatively low energy density and high initial irreversible capacity, but are likely to be part of first-generation sodium cells (CNRS News 2015).

This chapter aims to provide a general overview of the hard carbons explored so far in NIBs. In the first part of the chapter, we will focus on the description of the main synthesis routes used to prepare hard carbons with a focus on the impact of the precursor type and synthesis conditions on the hard carbon characteristics. Mainly, the structural, textural and surface chemistry aspects will be emphasized through several selected examples. The performance in half-cell and full-cell will be discussed in relation with the hard carbon properties in the second part of the chapter. The last part deals with the sodium storage mechanisms, which is critical, and yet still under debate.

\subsection{What is a hard carbon?}

"Hard" carbon designates a type of carbon material, which is not able to graphitize (transform into graphite) even if the heating temperature exceeds $2,500^{\circ} \mathrm{C}$ (Oberlin and Terriere 1975). The term "non-graphitizable", "disordered" and "nonorganized" carbon is widely used as synonyms. However, terms like "amorphous" and "non-graphitic" carbon are employed as well and should be avoided as recommended elsewhere (Dou et al. 2019) since hard carbon does not contain localized $\pi$-electrons as amorphous structures, while the "non-graphitic" term designate rather a state of carbon before graphitization process. The reason why hard carbon does not graphitize and does not have a long-range ordering along the c-axis is linked to its microstructure given by strongly cross-linked precursors. The early model used to describe such structure was proposed by Warren $(1934,1941)$, which considered it as randomly oriented graphitic nanodomains (Figure 3.1(a)). Later on, Franklin (1951) proposed a similar model, but in this case, the graphitic nanodomains are bonded by amorphous carbon (sp3) domains, which prevent graphitization and lead to micropore formation (Figure 3.1(b)). While these two models were proposed based on X-ray diffraction studies, more in-depth understanding of the hard carbons structure at nanometer scale was achieved by Harris and Tsang (1997) by using TEM analyses. In this model, the graphene curvature observed in TEM images is taken into consideration and related to fragmented fullerenes-like structures, that align in various degrees, composing the micropore walls (Figure 3.1(c)). This curvature stabilized by non-hexagonal structures is believed to prevent the graphitization. Other types of defects such as vacancies, interstitial heteroatoms and empty sites may deform the regularity of graphene sheets (Dou et al. 2019). The hard carbon structure is considered rather complex due to the presence of the different types of porosities as well. In this regard, the widely accepted model today describing the hard carbon structure is the "house of cards" or "falling cards" model (Figure 3.1(d)) proposed by (Dahn et al. 1997 and Buiel et al. 1999). This considers hard carbon as a mixture of pseudo-graphitic micro-crystallites (sp2 hybridized, turbostratic staked graphene layers) and amorphous regions (sp3 hybridized) along with nanovoids (nanopores). The temperature increase generally favors the nanopores coalescence and closure above $1,000^{\circ} \mathrm{C}$. 
(1941)

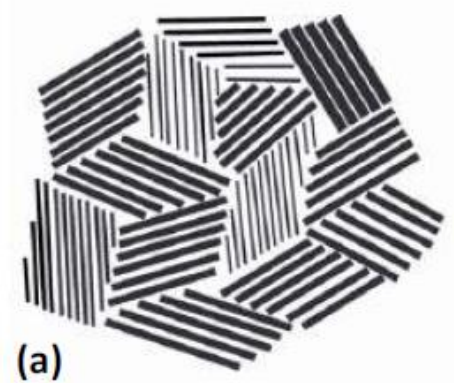

(1997)

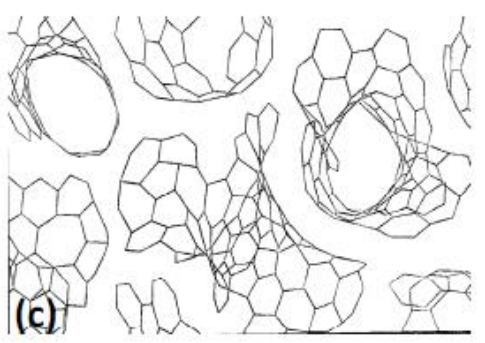

(1951)

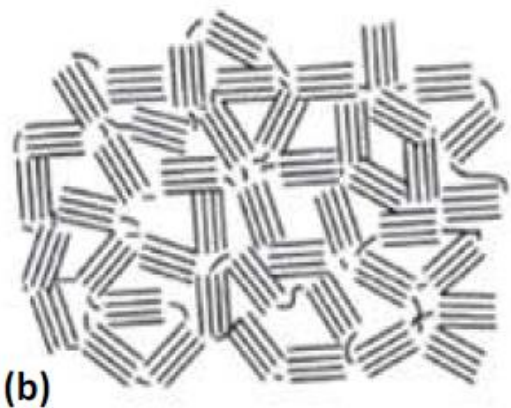

(1999)

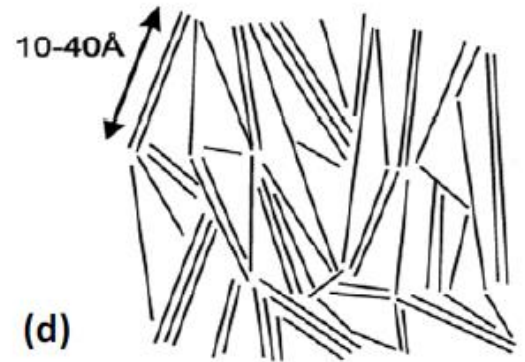

Figure 3.1. Hard carbon models as proposed by (a) Warren (1941), (b) Franklin (1950),(c) Harris and Tsang (1997) and (d) Dahn et al. (1999).Reprinted with permission from Warren et al. (1941 Copyright (1941) by the American Physical Society. Reprinted with the permission of Haris and Tsang 1997. Copyright (1997) Taylor \& Francis Ltd. Reprinted from Buiel et al. (1999). Copyright (1999), with permission from Elsevier.

During the synthesis of hard carbon by thermal annealing (pyrolysis) under inert atmosphere of a precursor, several events occur, highly dependent on the annealing temperature and precursor composition (Figure 3.2). Usually, water is seen below $100^{\circ} \mathrm{C}$ due to the dehydration/depolymerization reactions while a great amount of gases $\left(\mathrm{H}_{2} \mathrm{O}, \mathrm{COx}, \mathrm{CH}_{4}\right)$ is released at around $400^{\circ} \mathrm{C}$ as a result of precursor thermal decomposition, with the formation of a solid residue. Due to the released gas, microporous carbonaceous material is formed called char, which is not able to graphitize contrary to fused residues that are able to undergo graphitization (Kipling et al. 1964). At higher temperatures $\left(500-1000^{\circ} \mathrm{C}\right)$, the release of oxygen- and nitrogen-based functional groups and the removal of hydrogen from the structure leads to the formation of hard carbon (interlayer space, $\mathrm{d}_{002}$ comprise between 3.7 and $4.0 \AA$ ) (Zhang et al. 2016; Beda et al. 2018). The hydrogen amount observed in the precursor, could be linked in some extent to its ability to undergo fusion state and to be graphitized, i.e. a richer hydrocarbon precursor leading to graphitized carbon. Higher temperatures $\left(>2,000^{\circ} \mathrm{C}\right)$ lead to glassy carbon formation $\left(3.4 \leq \mathrm{d}_{002} \leq 3.6 \AA\right)$. The annealing conditions (temperature, type of gas, pressure and heating rate), the type of precursor (chemical composition and structure) and the synthesis conditions will impact the characteristics of hard carbons (porosity, structure, surface chemistry and defects) and in-fine their performance in NIBs. All these aspects will be developed in the following part. 


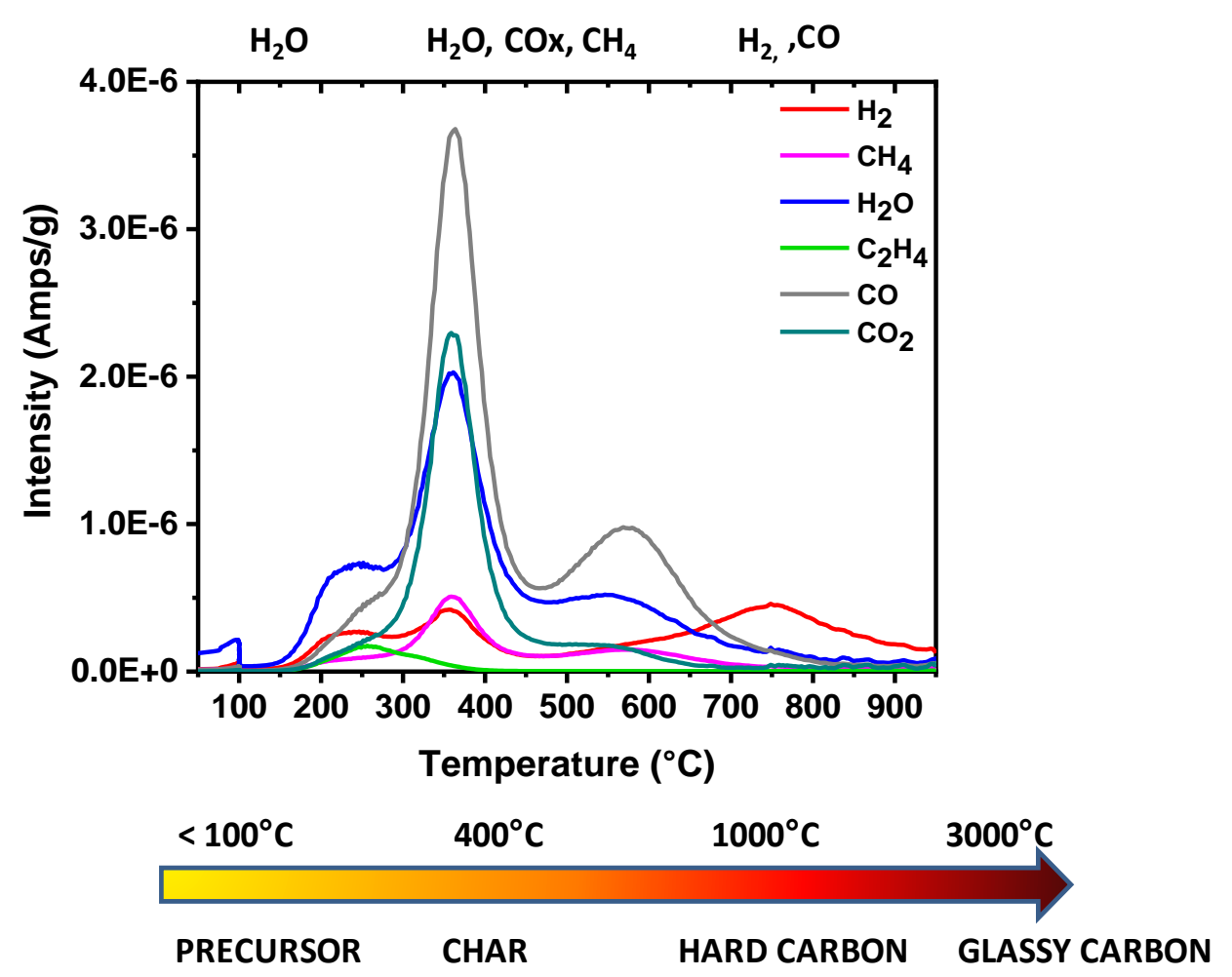

Figure 3.2. Temperature programmed desorption coupled with mass spectrometry showing the gas release profiles during the heating of a phenolic resin precursor. Reprinted from Beda et al. (2018). Copyright (2018), with permission from Elsevier.

\subsection{Hard carbon synthesis and microstructure}

Hard carbon is the first material that has achieved performance in Na-ion half-cells close to those of graphite in LIBs. Since the early 2000s, hard carbons have been reported from a wide range of precursors such as phenolic resins, sucrose, glucose, cellulose, cotton, pitch, lignin, wood, polyaniline (PANI), polyacrylonitrile (PAN) and various biomasses (banana/pomelo/apple peels, okara, leaves, algae, etc.). To easily differentiate between them, the precursors used to develop hard carbon materials which can be grouped into three main categories: synthetic polymers, biopolymers and raw biomass (Figure 3.3(a)). With the aim of finding the best precursor for the preparation of hard carbon, all three categories were approached owing to their own advantages.

The raw biomass is a convenient cheap precursor widely available as a renewable source of energy; this is the reason why it is widely used for hard carbon preparation (Figure 3.3(a)). However, biomass is not uniformly distributed over the world, it varies with the seasons and requires a lot of space to be stored (biomass plants), which may limit the availability. Moreover, the majority of the biomass present a significant amount of inorganic impurities in their composition, which may negatively affect the electrochemical performance, requiring a supplementary washing step generally with acids. Another crucial issue is the carbon yield after pyrolysis, which is lower ( 20\%) compared to other precursors, as seen in Figure 3.3(b). This low yield has the main disadvantages of a higher production cost and the release of a greater amount of undesirable COx gases during their pyrolysis.

Bio-polymers (cellulose, chitosan, lignin etc.), the second category often explored to produce hard carbons, are commercially available, biodegradable and sustainable with renewable sources of raw materials and thus a low cost. As in the case of biomass, the carbon 
yield is generally low ( $20 \%$ for cellulose, sucrose, glucose) (Narasimman and Prabhakaran 2013; Matei Ghimbeu et al. 2018) but for some precursors such as chitosan and lignin (Conder et al. 2019; Matei Ghimbeu et al. 2019), a higher yield ( 40-50\%) can be reached.

The last category is the synthetic polymers that are largely soluble in different solvents and possess a rich chemistry offering, as the main advantage, the possibility of adapting the synthesis procedure via chemical parameters in order to control carbon characteristics. Besides, the carbon yield obtained is usually high ( 40-50\% for phenolic resin and PAN). The yield of carbon depends on both precursor chemical composition and structure (Irisarri et al. 2018). The main disadvantage exposed by this class of precursors is their toxicity. For example, phenolic resins, widely used to obtain hard carbons, are made up of phenol and formaldehyde that are carcinogenic. The high price compared to the other precursors could be also a limitation for synthetic polymers, as seen in Figure 3.3(c).

In what follows, these three categories of precursors will be discussed in detail. The main synthesis procedures reported so far to obtain hard carbon will be presented in order to highlight the main changes observed in their characteristics (structure, texture, morphology, surface chemistry, defects, etc.).

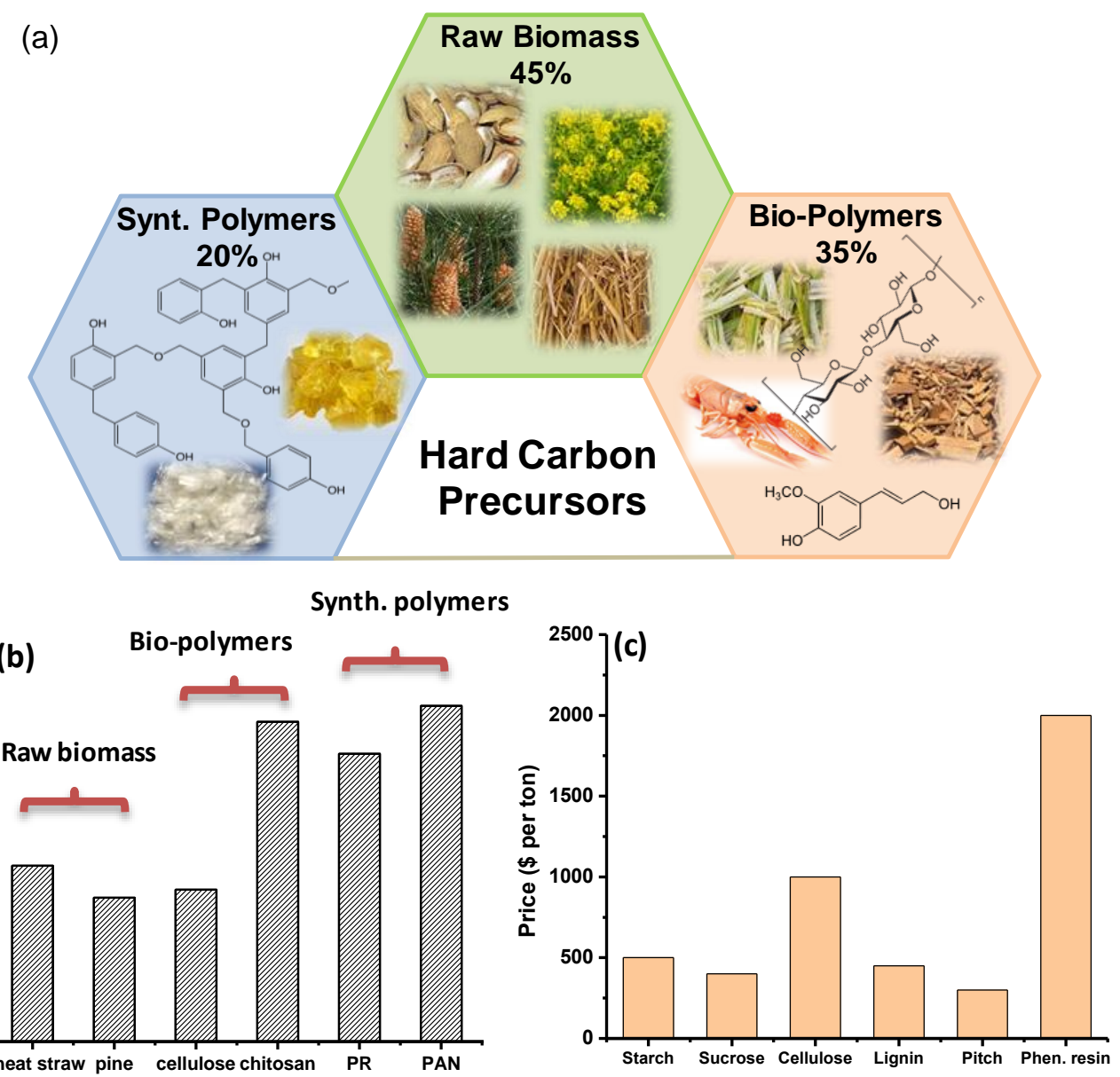

Figure 3.3. (a) Representation of the main categories of precursors used to prepare hard carbon and their percentage of use for hard carbon preparation determined based on recent publications; (b) carbon yield exhibited by different precursors belonging to the three main categories: raw biomass (wheat straw, pine; Saavedra Rios et al. 2018), bio-polymers (cellulose; Matei Ghimbeu et al. 2018), chitosan (Conder et al. 2019), synthetic polymers (phenolic resin; Beda et al. 2018) and PAN (Zhang et al. 2016) when thermally treated at $900^{\circ} \mathrm{C} ;($ c) price per ton of different precursors reported in literature (Li et al. 2015). 


\subsubsection{Synthetic precursors-based hard carbon synthesis}

Due to the high yield and synthesis flexibility they offer, synthetic precursors are often employed for hard carbon preparation. The most commonly used are phenolic resins, PAN and PANI. Phenolic resins are a family of aromatic compounds directly bonded with hydroxyl groups (Ku et al. 2010). They are especially interesting due to the possibility of controlling the microstructure and morphology of the hard carbon (Wang et al. 2017).

Generally, the simplest way to obtain hard carbon is the direct pyrolysis of the precursors at temperatures above $1,000^{\circ} \mathrm{C}$. In other cases, precursors pretreatments (hydrothermal carbonization [HTC], electrospinning, sol-gel and washing) or post-treatments (washing, activation and doping) are performed with the aim of modifying the morphology, structure and chemical functionalities of hard carbons.

One of the first reports on hard carbons derived from phenolic resins for NIBs was published by Wang et al. (2015). The phenolic resin was obtained by mixing phenol and formaldehyde followed by the addition of sodium hydroxide solution and formaldehyde in excess. Hard carbon microspheres were obtained by hydrothermal treatment $\left(500^{\circ} \mathrm{C}\right)$ followed by carbonization at high temperature $\left(800-1,500^{\circ} \mathrm{C}\right)$. In a different study, Li et al. (2016c) used commercial phenolic resins in combination with pitch (different ratios) to obtain hard carbon materials after carbonization under Ar flow at temperatures between 1,200 and $1,600^{\circ} \mathrm{C}$.

Another work implying commercial phenolic resins was published by Irisarri et al. (2018), where the authors studied the influence of the precursor type (cellulose and lignin) and the impact of pyrolysis temperature on the material microstructure and surface chemistry. Due to the high carbon yield $\left(68 \%\right.$ at $\left.500^{\circ} \mathrm{C}\right)$, high tap density $\left(0.7 \mathrm{~g}^{\cdot} \mathrm{cm}^{-3}\right)$ and reversible capacity, the phenolic resin proved to be the most suitable precursor for large-scale production. Hasegawa $e t$ al. (2015) showed promising electrochemical performance for NIBs, as well, when testing hard carbons made of macroporous phenolic precursors. The sol-gel process was used to prepare the phenolic gel by mixing resorcinol and formaldehyde in acidic ethanol solution. The carbonization temperature was varied from 800 to $3,000^{\circ} \mathrm{C}$. Zhang et al. (2017b) reported hard carbon prepared from a mixture of phenolic resin and sucrose in different ratios heat-treated at temperatures between 1,000 and $1,600^{\circ} \mathrm{C}$. As highlighted in the above-mentioned studies, most phenolic resins used to obtain hard carbons are based on phenol/formaldehyde, which is highly toxic for both humans and the environment. Only limited attempts to find non-toxic alternatives have been made. Hard carbons from "green" phenolic resins based on plant extracted precursors such as phloroglucinol and glyoxylic acid was reported (Beda et al. 2018). Simple dissolution of the precursors in water-based solvents, followed by aging and thermal treatment at different temperatures $\left(1,100-1,700^{\circ} \mathrm{C}\right)$, leads to hard carbons with various textures and structures.

Huang and his team published two articles in which lignin (Li et al. 2015) and phenolic resin (Li et al. 2016c) were mixed with pitch to increase the graphitization level of hard carbonderived materials (Qin et al. 2012). By controlling the ratio between pitch and lignin/phenolic resin, as well as the pyrolysis temperature, the authors obtained materials with distinct properties (structure and texture), which were further successfully used as anode for sodium storage.

PAN is widely used as a precursor for the production of carbon fibers (Zhao et al. 2017; Gao et al. 2018). Due to the low cost and high yield, possibility of developing hard carbons for sodium storage from such precursors was explored since early 2000's when Thomas and Billaud (2002) successfully used commercial PAN-based carbon fibers heat treated at $1,650^{\circ} \mathrm{C}$ and $2,100^{\circ} \mathrm{C}$ to reversibly intercalate Na-ions. However, the higher temperature treatment resulted in a lower d-spacing $(0.344 \AA)$, which proved to be limiting for sodium storage. Zhang et al. (2016) reported PAN derived hard carbons produced by electrospinning. A solution of PAN and DMF (dimethylformamide) is stretched into fibers by applying a high voltage (18 
$\mathrm{kV})$. The result is a fiber film that is first stabilized at $250^{\circ} \mathrm{C}$ to avoid PAN melting followed by thermal treatment in the range of $650-2,800^{\circ} \mathrm{C}$ resulting in hard carbons with distinct properties for a better understanding of $\mathrm{Na}$ ion storage mechanisms. Such synthesis method presents the advantage that the hard carbon film can be used as obtained in a half-cell sodium ion battery (no other additives). A similar approach is reported by Jin et al. (2014) who prepared lignin-PAN based binder-free electrodes by electrospinning. The ratio lignin-PAN was studied and the results showed that increased lignin content in the system (up to 1:1 wt.\%) leads to hard carbon properties more compatible with sodium storage application (larger d-spacing, higher disorder degree and lower specific surface area SSA). However, as viscosity increases with lignin addition, electrospinning process was affected at high concentration.

In order to enhance the electrochemical performance of carbon materials, doping with heteroatoms such as nitrogen (N), boron (B), sulfur (S) or phosphorus (P) is a common strategy used. Electrospinning method seems to be again preferred for Ndoped carbon preparation for NIBs. Zhen et al. (2014) report a complex synthesis method of N-doped hollow carbon nanofibers obtained by pyrolysis of polypyrrole nanofibers $\left(700^{\circ} \mathrm{C}\right.$ under $\left.\mathrm{N}_{2}\right)$ obtained using electrospun polycaprolactone as a template. In a different study, Wang et al. (2016b) fabricate flexible $\mathrm{N}$-doped carbon films using polyamic acid as a precursor. The free-standing anodes were obtained by carbonization at $650^{\circ} \mathrm{C}$ for $3 \mathrm{~h}$ under $\mathrm{Ar}$ atmosphere. As $\mathrm{S}$ radius (102 ppm) is larger than that of $\mathrm{N}(75 \mathrm{ppm})$, larger interlayer distance of carbon material was obtained, facilitating the sodiation-desodiation process. Remarkable electrochemical performance was reported by Ye et al. (2016) when using co-doped (N and S) hollow carbon spheres (HCSs) obtained from phenolic resins. The precursor is obtained by dissolving resorcinol/urea/thiourea and formaldehyde in water followed by addition of polymethyl methacrylate (PMMA) that acts as a template. A thermal treatment at $600^{\circ} \mathrm{C}$ under nitrogen gas leads to the hollow carbon nanospheres.

Although carbon doping is often used to boost a material's performance, the thermal treatment is usually done at low temperatures $\left(600-900^{\circ} \mathrm{C}\right)$ to preserve the heteroatoms in the structure; however, it is too low to obtain an optimal hard carbon structure.

\subsubsection{Bio-polymers derived hard carbon synthesis}

Polysaccharides are complex carbohydrate derivative structures that contain chains of linked monosaccharide subunits intermediate, recognized as an important class of bio-polymers (along with polynucleotides and polypeptides). Naturally, they can be found in plants (Liu et al. 2018), as well as in microbes and animal sources (Yu et al. 2018b). Plants, due to their availability and sustainability, are considered the most important source for production of different types of polysaccharides, i.e. cellulose (the most abundant naturally occurring polysaccharide), cotton, starch, pectin, sucrose and glucose. On the other hand, animal and microbial sources could be used as well to obtain bio-polymers: glycogen (animal and fungal cells), chitosan and chitin (arthropods), etc. Besides the wide availability and viability, polysaccharides present the advantages of low cost and along with their functional properties such as non-toxicity, biodegradability and biocompatibility, they are commonly used as precursors to prepare hard carbons for NIBs. One of the first studies on sodium storage using polysaccharides-derived carbons was published by Stevens and Dahn in the 2000s. They reported a glucose-derived hard carbon that was able to deliver very promising capacity when treated at $1,100^{\circ} \mathrm{C}\left(\sim 300 \mathrm{mAh} \cdot \mathrm{g}^{-1}\right)$ proving that such carbons can successfully store sodium ions. A few years later (2002), Thomas and Billaud published similar results using cellulose fibers heat treated at $1,000^{\circ} \mathrm{C}$. However, in the following years, very little attention has been given to sodium technology and after a long break, in 2013, Ponrouch et al. published a new 
report on hard carbon derived from sugar. The anode material was obtained by simple pyrolysis at $1,100^{\circ} \mathrm{C}$ for $6 \mathrm{~h}$ under Ar flow and employed for electrolyte optimization for NIBs (Ponrouch et al. 2013). In the next years, polysaccharides were widely used to prepare hard carbons with the aim of getting materials that deliver high capacity and ICE, as well as long-term stability. Bommier et al. (2014) tried to predict the capacity of hard carbon in sodium batteries based on materials porosity by using sucrose-derived hard carbon. The materials were obtained in two steps: sucrose dehydration at $180^{\circ} \mathrm{C}$ for $24 \mathrm{~h}$ followed by pyrolysis at temperatures between $800^{\circ} \mathrm{C}$ and $1,100^{\circ} \mathrm{C} . \mathrm{CO}_{2}$ activation was performed as well in the attempt to enhance the materials capacity. Based on their results which suggest that sodium storage is more favorable for low porosity materials, they further doped sucrose with graphene oxide (acts as dehydration agent) to lower hard carbon specific surface area down to $5.4 \mathrm{~m}^{2} \cdot \mathrm{g}^{-1}$ and thus improve their performance (Luo et al. 2015). As result, ICE\% improved from $74 \%$ to $83 \%$ while maintaining 95\% capacity retention after 200 cycles. Using the same precursor but a different approach, i.e., pyrolysis at $1,100^{\circ} \mathrm{C}$ for $6 \mathrm{~h}$ followed by physical vapor deposition to obtain a carbon coating of about $2 \mathrm{~nm}$ thick, Ponrouch and Palacin (2015) succeeded in enhancing the performance of the hard carbon due to the decrease in SSA. The synthesis procedures involving carbohydrates are indeed simple but two practical issues limit such precursors for large-scale applications, i.e., they expand during the thermal treatment while the carbon yield is low in some cases (see Figure 3.1(b)). To overcome these problems, new approaches had to be explored and HTC prior to the pyrolysis step is one of the most used strategies. Väli et al. (2016, 2017a, 2017b) prepared hard carbons (for $\mathrm{Na}^{+}, \mathrm{K}^{+}$and $\mathrm{Li}^{+}$storage) from D-glucose via HTC. An aqueous solution of glucose is first thermally treated in an autoclave at $200^{\circ} \mathrm{C}$ for $24 \mathrm{~h}$, then washed, dried and pyrolyzed at $1,100^{\circ} \mathrm{C}$ for $2 \mathrm{~h}$ under Ar flow. Additionally, with the purpose to reduce surface functional groups, an additional treatment at $800^{\circ} \mathrm{C}$ under $\mathrm{H} 2$ is performed. In a more recent study, Yamamoto et al. (2018), explored several polysaccharides precursors: glucose, sucrose, maltose, cellulose, glycogen and amylopectin, which were preheated at 180, 275, 300 and $350^{\circ} \mathrm{C}$ for $12 \mathrm{~h}$ followed by thermal annealing at $1,300^{\circ} \mathrm{C}$ for $1 \mathrm{~h}$ under Ar flow. The authors found that cellulose-derived hard carbon preheated at $275^{\circ} \mathrm{C}$ delivers the highest reversible capacity. Moreover, it was pointed out that cellulose pretreatment at $275^{\circ} \mathrm{C}$ induces a high cross-linking between polymer chains, which favors micropore formation that will contribute to capacity increase. Other similar reports where cellulose is stabilized prior to the thermal treatment could be found in addition, in the literature (Luo et al. 2013; Zhu et al. 2017a). Hard carbon derived from cotton precursors have been reported as well (Li et al. 2016b). A simple heat treatment $\left(1,000-1,600^{\circ} \mathrm{C}\right)$ leads to hard carbon materials with interesting features for sodium storage (low surface area and high disorder degree).

Shen et al. propose a different approach. Instead of developing powder hard carbons, a self-standing electrode was obtained from cellulose wood fibers (Shen et al. 2015). The synthesis procedure consists of filtering a dispersion of softwood pulp and water leading to a cellulose fiber paper, which is first dried at $80^{\circ} \mathrm{C}$ and then carbonized at $1,000^{\circ} \mathrm{C}$, under Ar. Because the specific surface area was high $\left(590 \mathrm{~m}^{2} \cdot \mathrm{g}^{-1}\right)$, a pretreatment with $2,2,6,6-$ tetramethylpiperidine-1-oxyl (TEMPO) was done to lower it $\left(130 \mathrm{~m}^{2} \cdot \mathrm{g}^{-1}\right)$. The advantage of developing self-sustained electrodes relies on the absence of polymeric binder, solvent, conductive carbon and

current collector, and thus the price and the total weight can be reduced while the performance delivered are related just to the active material.

It can be pointed out that all these studies are limited to laboratory scale and only small amounts of materials are prepared. Palacin et al. (Irisarri et al. 2018) tried to optimize hard carbon synthesis and their performance for large-scale applications by tuning syntheses protocols and set-ups. Excellent performance was reported for pyrolyzed cellulose derived hard carbons while using a high loading of $500 \mathrm{~g}$ per heat treatment tube. 


\subsubsection{Biomass-based hard carbon synthesis}

Recently, there is an increasing interest in the research community for biomass-based hard carbon electrodes, as can be seen from Figure 3.3(a). This interest is mainly related to the valorization of biowastes to obtain high-quality materials from lower cost precursors compared to other sources (Górka et al. 2016). Additionally, the processing of specific biomass precursors, such as lignocellulosic biomass, is a carbon neutral cycle, which implies that the production of hard carbon actually leads to the sequestration of $\mathrm{CO}_{2}$.

Biomass can be technically defined as a complex, organic solid product of nonfossil nature obtained from natural or anthropogenic processes (Vassilev et al. 2012). It comprises the fraction of the biodegradable matter coming from products, wastes and residues from the biological origin (vegetal or animal), and the biodegradable fraction of municipal and industrial wastes (EUR-Lex n.d.). Vassilev et al. (2012) classify biomass into six main groups, according to the biological diversity, source and origin of the solid, as follows: (1) wood and woody products, (2) herbaceous and agricultural products, (3) aquatic products, (4) animal and human wastes, (5) industrial biomass wastes and (6) mixture of the one to five categories. Vegetal origin biomass, such as types 1 and 2 in the previous classification, is called lignocellulosic biomass and it is the main type of biomass used in research to produce hard carbon, given its chemical composition, availability and low cost (Dou et al. 2019). Lignocellulosic biomass is mainly composed of three structural biopolymers found in the secondary cell wall of plants: cellulose, hemicellulose and lignin (Meents et al. 2018), together with other minor nonstructural compounds such as extractives, inorganic compounds and moisture.

The main inorganic elements found in lignocellulosic biomass are nitrogen, chlorine, calcium, potassium, magnesium, sulfur, silicon, manganese, sodium, phosphor, iron and heavy metals. These elements are present in the organic matrix as water-soluble compounds, salts, minerals or mineraloids or organically bounded to the carbon, hydrogen and oxygen of cellulose, hemicellulose and lignin. Inorganic matter in lignocellulosic biomass is mostly nonvolatile and thus gathered as the remaining fraction after combustion called ash. Ashes composition may include phosphates, carbonates, silicates, chlorides, sulfates, oxides, hydroxides and nitrates which may impact the electrochemical performance of the materials. Figure 3.4 provides a representation of the organization of biomass components at different scales. It is challenging to present a typical lignocellulosic biomass composition given its high variability; so as a general overview, one can consider that cellulose content can be up to $50 \%$ in dry mass percentage, while hemicellulose, lignin and extractives can take values up to $30 \%$, $30 \%$ and $10 \%$, respectively. Ashes content may be as high as $60 \%$ for some biomasses (Vassilev et al. 2012).

The most used biomass precursors for hard carbon reported in the literature are a wide variety of fruits wastes (Wu et al. 2016; Wang et al. 2017a; Izanzar et al. 2018; Zhu et al. 2018), fruit peels (Lotfabad et al. 2014; Xiang et al. 2017; Li et al. 2018; Talekar et al. 2018), shells of different varieties of nuts (Lv et al. 2015; Wang et al. 2016a; Dahbi et al. 2017; Dou et al. 2017; Kim et al. 2017; Xu et al. 2018; Zhang et al. 2018b) or agro-industrial residues (Jiang et al. 2016; Cao et al. 2017; Dou et al. 2017; Saavedra Rios et al. 2018; Wang et al. 2018a)). Other types of vegetal biomass such as lotus stem (Zhang et al. 2018a), pinecones (Zhang et al. 2017c), pine pollen grains (Zhang et al. 2018c), old loofah (Yu et al. 2018a), sorghum stalk (Zhu et al. 2017b), ramie fiber (Jiang et al. 2016), switchgrass (Zhang et al. 2017a) and pine wood and beechwood residues (Saavedra Rios et al. 2018). However, less common precursors of non-lignocellulosic nature, such as humic acid (Zhu et al. 2017c), chitosan/chitin (Conder et al. 2019) and algae (Meng et al. 2015), have been reported with competitive performance of NIBs. 


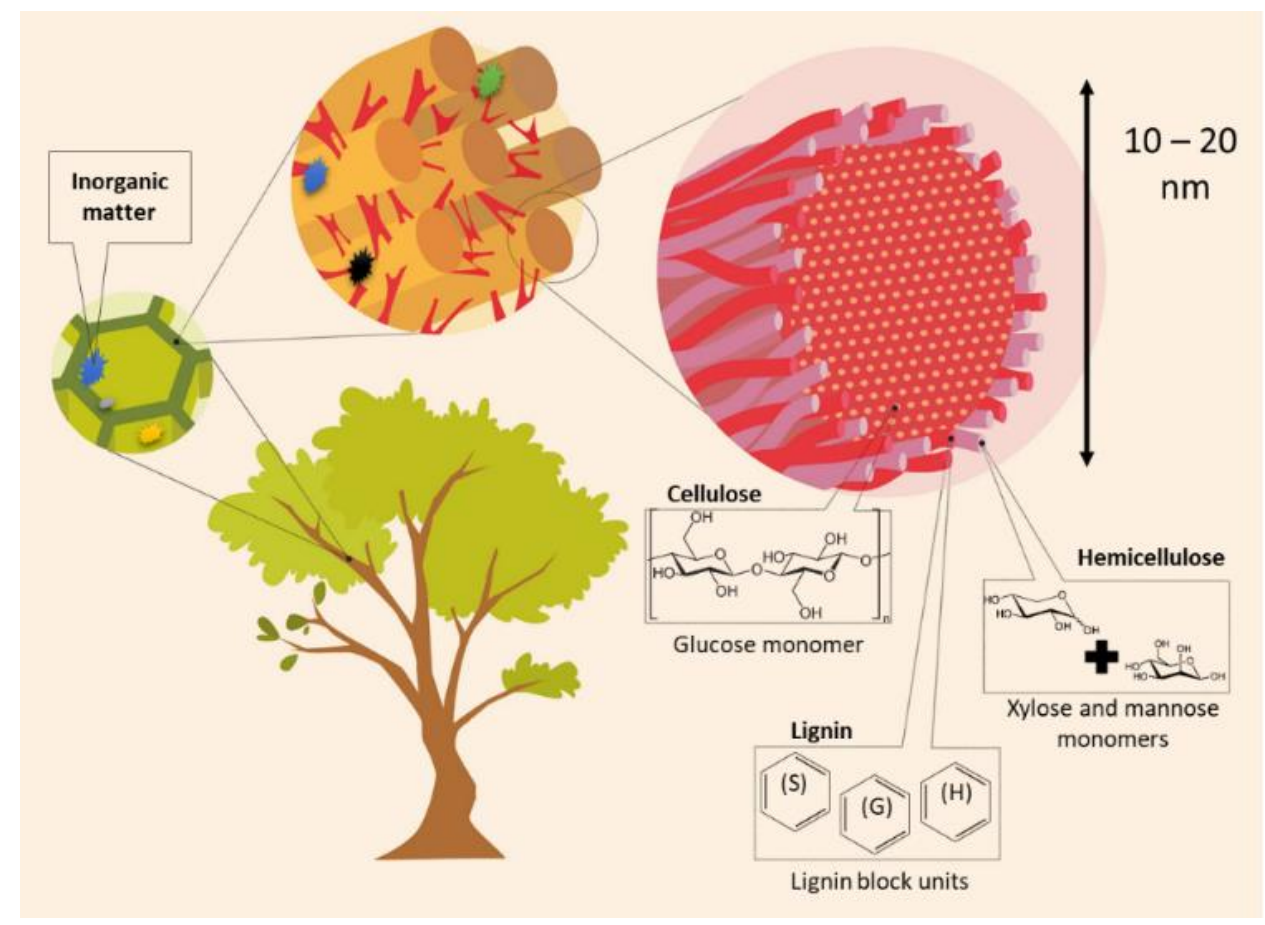

Figure 3.4. Schematic representation of lignocellulosic biomass structure (credit to Juana Molina).

Hard carbons are mainly synthesized by pyrolysis under inert atmosphere, with prior or post-treatment to purify the carbonaceous materials. Studies commonly explore pyrolysis temperatures between $600^{\circ} \mathrm{C}$ and $1,600^{\circ} \mathrm{C}$ (Górka et al. 2016). Slow heating rates $\left(<10^{\circ} \mathrm{C} \cdot \mathrm{min}-1\right)$ enhance hard carbon yield (Anca-Couce 2016$)$ and allow to better retain the original biomass morphology (Haas et al. 2009). New porosity is created in the solid upon pyrolysis, and a maximum in the specific surface area is commonly seen between 600 and $800^{\circ} \mathrm{C}$ for woody biomass (Anca-Couce 2016). At higher temperatures, the specific surface area decreases because of the pore blocking by tar's secondary reaction products, giving place to closed pores (Rodríguez-Reinoso and Molina-Sabio 1992).

Biomass moisture content is an essential factor when classifying biomass for thermochemical conversion processes, such as pyrolysis. In this perspective, raw materials are separate into dry $(<60 \%$ moisture) and wet $(\geq 60 \%$ moisture) biomass. Dry biomass can undergo direct pyrolysis while wet biomasses are not suitable for direct pyrolysis given a high energetic consumption for drying the elevated moisture content. In this case, pretreatments such as HTC can be performed.

In HTC, the biomass precursor undergoes thermal degradation in a water reaction medium, between 180 and $250^{\circ} \mathrm{C}$, under the self-generated pressure of a closed system (5-10 MPa) (Kumar et al. 2018; Wang et al. 2018b; Rodriguez Correa et al. 2019). The main products are a solid residue called hydrochar, and a liquid phase containing aqueous and organic phases. A small quantity of gas is also generated and mainly composed of $\mathrm{CO}_{2}$ (Wang et al. 2018b). The hydrochar obtained has different physicochemical properties than those of chars obtained from direct pyrolysis, given that the degradation of biomass is done by different mechanisms. Hydrochars normally retain less ash content in the carbonaceous structure given that the inorganic elements dissolve into the liquid phase. Because of the continuous re-condensation reactions, hydrochars have a lower surface area than chars, resulting in the constant blocking of the pores. 
Strong acid/base treatment is another pretreatment of the biomass precursor prior to pyrolysis. It is used to remove inorganic elements from raw biomass (Cao et al. 2017; Zhang et al. 2017c, 2018a, 2018c). Zhang et al. (2017c) and Dahbi et al. (2017) compared hard carbons obtained from chemically treated (with $\mathrm{KOH}$ and $\mathrm{HCl}$ solutions) and untreated pinecone and argan shell precursors. Authors found that potassium was the most abundant metal and in general, washed samples exhibit better retention capacities and rate capabilities than the unwashed ones. Washed samples may contain more active sites for sodium storage given the removal of the metals. Acid treatment seems to induce differences in the structural parameters such as higher graphitization degree and less presence of defects while enhancing the hard carbon yield. However, the punctual effect of the inorganic constituents of biomass in electrochemical performance of hard carbon still needs to be studied.

Some authors (Wu et al. 2016; Kim et al. 2017; Hasa et al. 2017; Xiang et al. 2017) employed these chemical treatments to obtain activated hard carbons (AHC) with a high specific surface area (between 200 and $800 \mathrm{~m}^{2} \cdot \mathrm{g}^{-1}$ ), arguing that it is beneficial for the electrolyte percolation and sodium storage, despite the fact that Coulombic efficiency is drastically reduced. Xiang et al. (2017) activated orange

peels to make high specific surface area hard carbons. Non-AHC were prepared by direct pyrolysis at $800^{\circ} \mathrm{C}$. For $\mathrm{AHC}$, orange peels were first washed with $7 \% \mathrm{KOH}$ solution, pyrolyzed at the same conditions as non-AHC samples, and then grounded and dispersed in $2 \mathrm{M} \mathrm{HCl}$ solution. The resulting AHC had a specific surface area of $638 \mathrm{~m}^{2} \cdot \mathrm{g}^{-1}$, while non-AHC had 357 $\mathrm{m}^{2} \cdot \mathrm{g}^{-1}$. Additionally, in AHC the higher fraction of the pore volume was made up of micropores of $0.7 \mathrm{~nm}$, while non-AHC presented mostly mesoporous with a larger pore volume fraction centered at $8 \mathrm{~nm}$. Concerning electrochemical behavior, authors report a high first insertion capacity of $497 \mathrm{mAh} \cdot \mathrm{g}^{-1}$ for $\mathrm{AHC}$ and $350 \mathrm{mAh} \cdot \mathrm{g}^{-1}$ for non-AHC at $0.5 \mathrm{~mA} \cdot \mathrm{g}^{-1}$. However, ICE in both cases is very low, around $40 \%$. AHC presents better charge/discharge performance, better rate capability and stability through 1,000 cycles when compared to non-AHC.

Lignocellulosic biomass exhibits natural occurring morphology and porosity that may also enhance electrolyte percolation, ionic and electronic conductivity. Zhang et al. (2018a) have studied this feature using as precursor lotus stems from China. Lotus stem has an intrinsic hierarchical structure of channels in the longitudinal axis, which leads to the formation of a controlled three-dimensional structure after pyrolysis. The resulting hard carbon pyrolyzed at $1,400^{\circ} \mathrm{C}$ exhibits the first reversible capacity of $351 \mathrm{mAh} \cdot \mathrm{g}^{-1}$ with an ICE of $70 \%$ at a current density of $40 \mathrm{~mA} \cdot \mathrm{g}^{-1}$, for a low surface area of $24.3 \mathrm{~m}^{2} \cdot \mathrm{g}^{-1}$. In parallel, pollen grains exhibit a unique morphology of hollow spheres. Li et al. (2017a) synthesized hard carbon from pollen grains to expose the hollow carbon reticulate matrix in order to enhance diffusion of ions and conductivity of electrons. Hydrothermal treatment was used to get through the reticulated structure without damaging it and pyrolysis aimed to preserve this structure. Low pyrolysis temperature of $600^{\circ} \mathrm{C}$ produced the samples with the best performance in both reversible capacity $\left(135 \mathrm{mAh} \cdot \mathrm{g}^{-1}\right.$ at $\left.100 \mathrm{~mA} \cdot \mathrm{g}^{-1}\right)$ and rate capability $\left(50 \mathrm{mAh} \cdot \mathrm{g}^{-1}\right.$ at $\left.2 \mathrm{~A} \cdot \mathrm{g}^{-1}\right)$. Only $10 \%$ of the capacity was lost after 1,000 cycles at $100 \mathrm{~mA} \cdot \mathrm{g}^{-1}$.

\subsection{Hard carbon characteristics}

Given the complexity of hard carbon structure, several analytical techniques are used to elucidate it, and subsequently to understand its relation with the electrochemical performance. The most common analysis of hard carbon microstructures comprises structural techniques such as X-ray diffraction (XRD), small angle X-ray scattering (SAXS), transmission electron microscopy (TEM), and Raman spectroscopy; porosity and surface area measurements using gas adsorption-desorption isotherms, surface chemistry analysis via X-ray photoelectron spectrometry (XPS), energy dispersive X-ray spectroscopy (EDX) and temperature 
programmed desorption coupled with mass spectrometry (TPD-MS). The final hard carbon structure and properties are strongly dependent on several factors, i.e., the initial precursor nature, the synthesis conditions and the final pyrolysis temperature being one of the critical parameters. The following section will briefly describe these techniques applied for hard carbon analysis along with the main important parameters that can be tuned in order to achieve the optimal hard carbon characteristics for Na-ion storage.

\subsubsection{Hard carbon structure}

The XRD technique uses an incident X-ray source that scatters against the atomic lattice of a given material to obtain information about its structure at the local scale (Bommier et al. 2018; Dou et al. 2019). It is mainly used for characterizing crystalline structures such as graphite, however, disordered carbons also present domains of randomly stacked graphene layers, allowing them to obtain structural information from this technique when applied to hard carbons. As a result, a typical diffraction pattern of hard carbon structure exhibits very broad diffraction peaks for $00 l(002)$ and asymmetrical $h k 0(10)$, (11) lines, related to the reflection of the basal graphene planes and perpendicular to them, respectively (Inagaki and Kang 2016), as presented in Figure 3.5(a). The (002) broad feature in hard carbon diffraction pattern represents the average distance between each graphene layer in the domain and is used to estimate the thickness of the domain (Lc) along the c-axis. The (10) signal is used to estimate the width of the domain (La) along the a-axis (Bommier et al. 2018) by using the Scherrer equation: $L_{\mathrm{a}, \mathrm{c}}=\frac{k \lambda}{B \cos \theta}$, where $k=0.9$ for $\mathrm{L}_{\mathrm{c}}$ and 1.84 for $\mathrm{L}_{\mathrm{a}}$; B is the full width at half-maximum intensity for each feature.
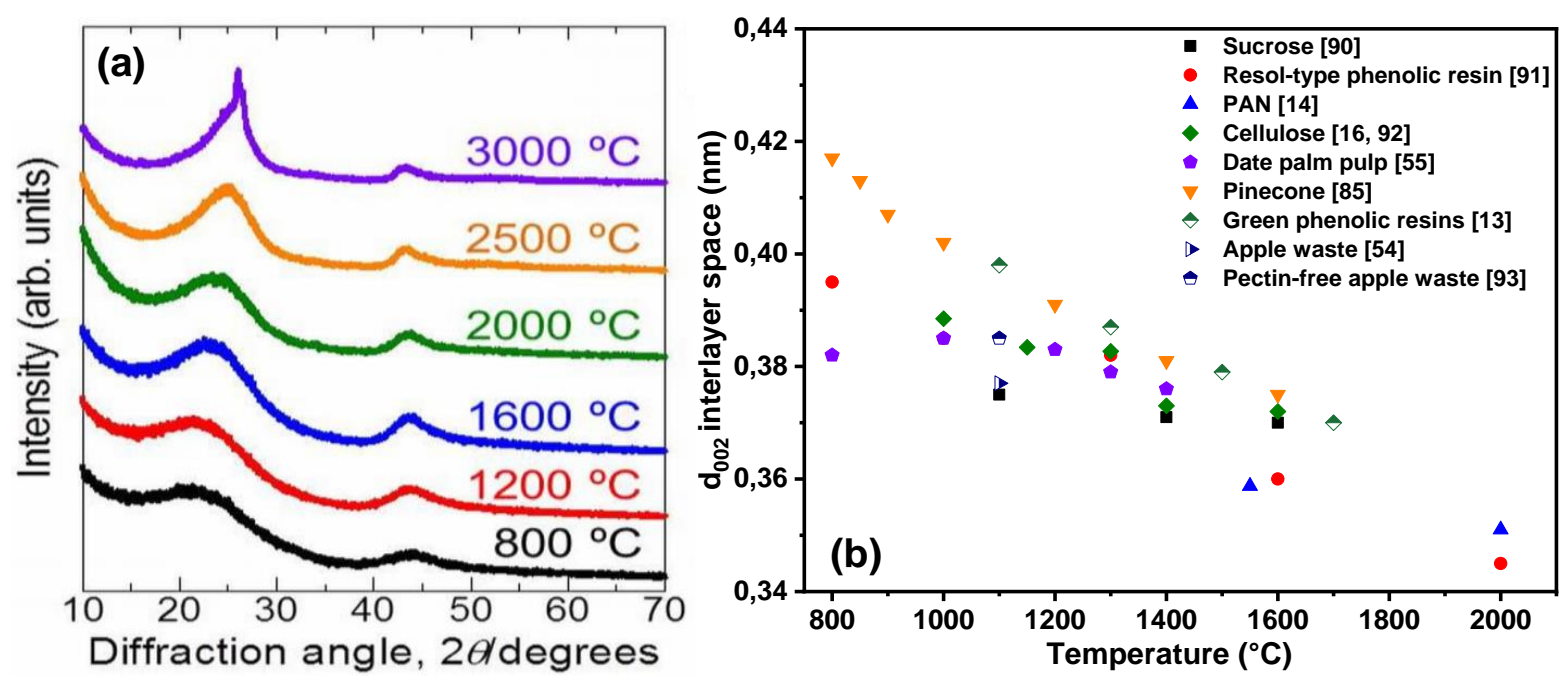

Figure 3.5. (a) XRD pattern for hard carbon derived from phenolic resin, synthesized at different temperatures (adapted from Hasegawa et al. 2015). (b) Evolution of the interlayer space (d002) with heat treatment of various precursors: sucrose (Bommier et al. 2015), phenolic resin (Zhang et al. 2011), PAN (Zhang et al. 2016), Cellulose (Simone et al. 2016) (Matei Ghimbeu et al. 2018), Date palm pulp (Izanzar et al. 2018), Pinecone (Zhang et al. 2017c), Green phenolic resins (Beda et al. 2018), apple waste (Wu et al. 2016), pectin-free apple waste (Dou et al. 2018).

With the increase in the thermal treatment temperature, the graphene layers in hard carbon structure tend to get closer, as it is evidenced by the thinner diffraction features and a shift of the (002) diffraction peak toward higher 2 theta angles (Figure 3.5(a)), indicating a 
decrease in the distance between layers. In parallel, a growth in the domain is also observed, in both width (La) and thickness (Lc). Figure 3.5(b) shows literature-reported data for the diminution of the calculated $\mathrm{d}_{002}$ distance for different hard carbon precursors upon heat treatment. Notice also, that for a given temperature, the structure varies from one precursor to another. In parallel, for the same precursor, the chemical synthesis conditions influence the final hard carbon structure, as can be seen from the green phenolic resins obtained by varying the solvent and the drying conditions (Beda et al. 2018). Dou et al. (2018) and Wu et al. (2016) produced hard carbons from pectin-free pomace and apple waste, respectively, founding that the absence of pectin in the precursor and the acid pretreatment also had an influence on the final structure of the hard carbon.
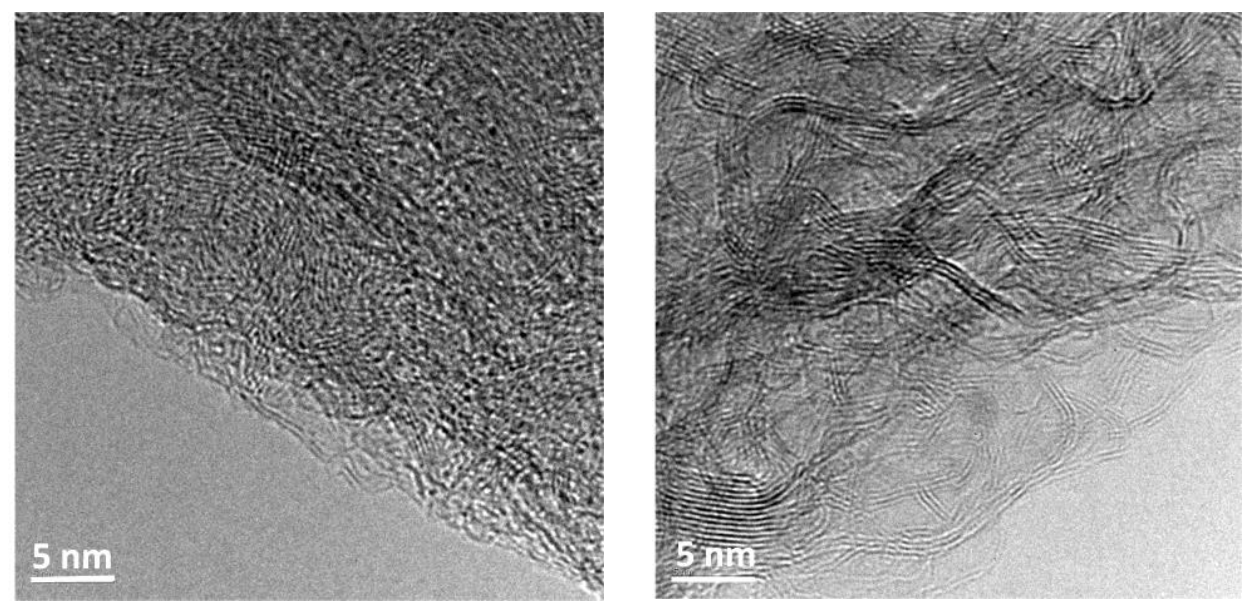

Figure 3.6. TEM micrographs of PAN-derived hard carbon at (a) $1,550^{\circ} \mathrm{C}$ and (b) $2,200^{\circ} \mathrm{C}$ (Zhang et al. 2016).

Using the TEM technique, the local nanostructure of hard carbons can be observed and it is possible to evidence the presence of the distorted graphitic domains in the materials. As for XRD, TEM micrographs give evidence of an increment in the graphitization degree at higher temperatures, showing what is thought to be the alignment of more and larger graphene layers with temperature, as can be seen from Figure 3.6. In addition, it is possible to identify empty spaces between the domains, corresponding to the closed porosity in the structure. The highresolution TEM (HR-TEM) technique allows further analysis of disordered carbons. Bommier et al. (2018) enlisted that recent reports deal with the estimation of the lattice fringe length, tortuosity and average curvature of graphene sheets, applied for hard carbon structure elucidation.

\subsubsection{Hard carbon porosity}

Surface area, open porosity and closed porosity are key parameters to investigate for hard carbon materials. It is well known that the greater the surface area, the highest the irreversibility, given the SEI formation (Dou et al. 2019). However, surface area allows better electrolyte percolation, and therefore, it is needed in some extent for a high power capability (Saurel et al. 2018). Although less studied and difficult to quantify, the closed porosity is thought to be an important factor contributing to sodium ions storage by bulk diffusion mechanisms (Saurel et al. 2018; Dou et al. 2019). To measure the open porosity and surface area, the most employed technique is $\mathrm{N}_{2}$ adsorption-desorption. Normally, non-pretreated hard carbon exhibits low surface area derived from the $\mathrm{N}_{2}$ adsorption measurement for temperatures above $1,000^{\circ} \mathrm{C}$ (Figure 3.7(a)). However, Matei Ghimbeu et al. (2018) performed a study with 
cellulose-derived hard carbons, revealing that $\mathrm{N}_{2}$ adsorption isotherms give limited information about the microporosity of the material. They used $\mathrm{CO}_{2}$ as analytic gas and revealed that the derived surface area was significantly higher. The smaller size of the $\mathrm{CO}_{2}$ molecule, together with a better diffusion behavior favored by the higher analysis temperature $\left(273 \mathrm{~K}\right.$ for $\mathrm{CO}_{2} \mathrm{vs}$. $77 \mathrm{~K}$ for $\mathrm{N}_{2}$ ), allows $\mathrm{CO}_{2}$ molecule accessing smaller pores called ultramicropores (pore size < $0.7 \mathrm{~nm}$ ) (Matei Ghimbeu et al. 2018). Although the role of such small pores on Na storage is not yet understood, they certainly impact molecule adsorption (water, electrolyte), material density, defects, etc. Figure 3.7(a) gathers the surface area determined from the $\mathrm{N}_{2}$ isotherms for hard carbons synthesized at different temperatures and from different precursors. The $\mathrm{CO}_{2}-$ derived surface areas are also presented for some of the hard carbons, since only few works provided such information (Figure 3.7(b)). Worth to note that $\mathrm{CO}_{2}$ measurements lead to higher surface area values; however, above a given temperature, the surface area tend to reach the low values similar to those calculated from $\mathrm{N}_{2}$ isotherms due to the pore closure (Dou et al. 2019).
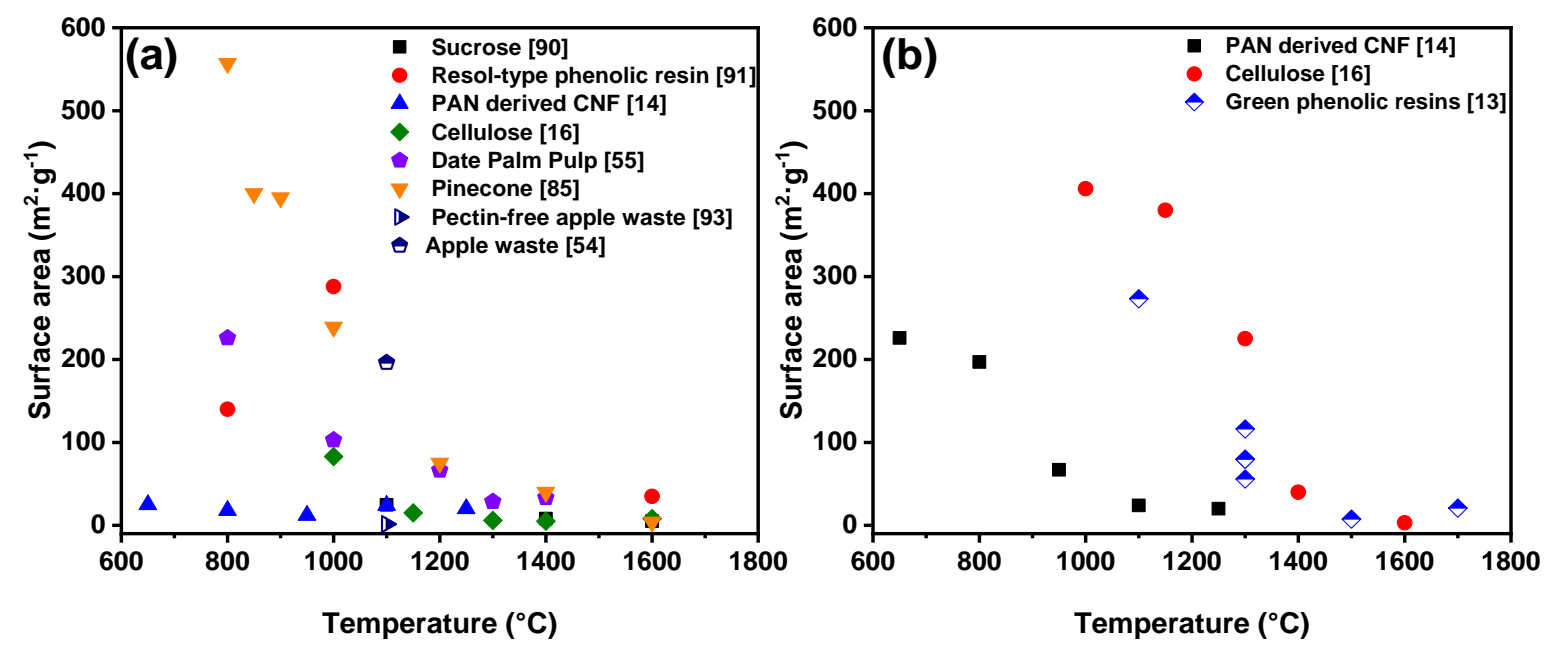

Figure 3.7. Surface area values determined from (a) $\mathrm{N}_{2}$ and (b) $\mathrm{CO}_{2}$ adsorption measurements for different precursors and different synthesis conditions, reported in various studies: sucrose (Bommier et al. 2015), phenolic resin (Zhang et al. 2011), PAN (Zhang et al. 2016), Cellulose (Simone et al. 2016) (Matei Ghimbeu et al. 2018), Date palm pulp (Izanzar et al. 2018), Pinecone (Zhang et al. 2017c), Green phenolic resins (Beda et al. 2018), apple waste (Wu et al. 2016), pectin-free apple waste (Dou et al. 2018).

As mentioned before, the augmentation of the annealing temperature reduces the microporosity and induces the coalescence of the micropores to larger pores and the reorganization of the graphene layers into closer layers (Matei Ghimbeu et al. 2018). As for XRD analysis, notice that the precursor and the synthesis conditions drastically affect the surface area of the final hard carbons. Green phenolic resins precursors present very dispersed values of surface area, by $\mathrm{N}_{2}$ and $\mathrm{CO}_{2}$ measurements. The solvent in which the resin is prepared has a major impact on the final hard carbon porosity. The composition of the precursor, as well as the application of an acid pretreatment leads to different porosity in the material. It is confirmed by the pectin-free pomace (Dou et al. 2018) and the conventional apple waste derived hard carbons (Wu et al. 2016), in which the former has a much lower surface area compared to the latter. Worth to note that the chemical composition of the precursor is important also since oxygen-free precursors such as PAN exhibit much lower specific surface areas than the other precursors containing oxygen in their structure. 

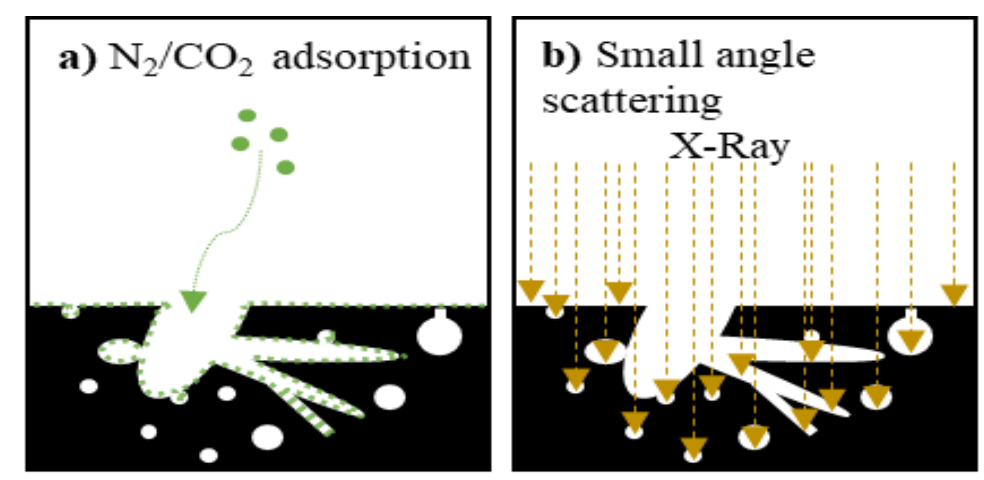

Figure 3.8. Comparison between (a) gas adsorption (quantification of open pores including partially closed ink-bottle pores) and (b) small angle scattering techniques (analysis of all porosity, including closed pores). Adapted with permission from Saurel et al. (2018). Copyrights (2016) to John Wiley and Sons.

However, although gas adsorption provides useful information about the presence of ultramicropores, micropores and mesopores, in most of the cases, the isotherms and pore size distribution are not provided, which limits the understanding of hard carbon porosity. In addition, this technique does not allow quantifying the closed porosity but made possible by SAXS, which is sensitive to all the pores present in the structure by using the electronic density difference between the carbon matrix and the empty space of pores (Saurel et al. 2018). A schematic representation of open and closed porosity analyzed by gas adsorption and SAXS techniques is presented on Figure 3.8. SAXS uses an incident X-ray beam that diffuses into the sample. The diffused signal is then received by a detector and the intensity (which is proportional to the difference in electronic density) is plotted as a function of the $2 \theta$ scattering angle, or scattering vector $\mathrm{Q}$ (where $\mathrm{Q}=4 \pi \sin (\theta) \cdot \lambda-1$, and $\lambda$ is the wavelength of $\mathrm{Cu} K \alpha=$ $1.5418 \AA$ ).

Some SAXS patterns for char and hard carbons from cellulose synthesized at different temperatures are shown in Figure 3.9(a). At small Q values (under $0.05 \mathrm{~nm}-1$ ), the intensity signal decreases showing a Q-4 behavior characteristic of well-defined interfaces, such as meso- and macropores of bulk particles. When the signal drop shifts to a $\mathrm{Q}-3$ behavior, the interface boundary is not well defined (Simone et al. 2016). Then, a plateau zone followed by a sharp decreasing curvature is characteristic of ultramicroporosity, which also comprises the closed porosity (Dou et al. 2019). A proper fitting of this curve allows quantifying the radius of gyration $(\mathrm{Rg})$ of these pores, and therefore a pore volume. As for gas adsorption measurements, SAXS results also vary with heat treatment. For hard carbons produced from commercial cellulose by Simone et al. (2016). The intensity of the SAXS profile increased with the temperature treatment, the Rg increases with temperature in a nonlinear behavior and the pore number decreases, as it is shown in Figure 3.9(b). Recent works also proposed to combine $\mathrm{N}_{2}$ adsorption measurements with He pycnometry to quantify the ratio between the closed and open pores (Dou et al. 2018; Zhang et al. 2018a). 

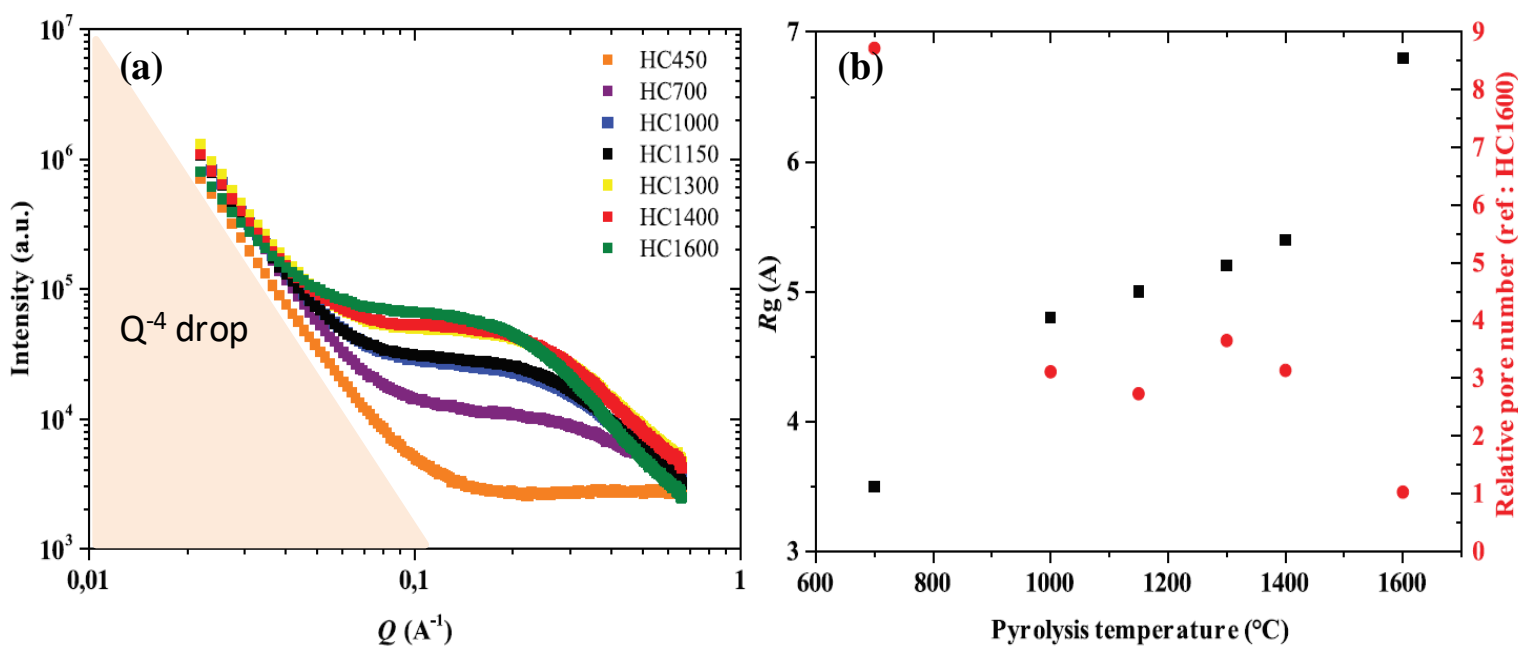

Figure 3.9. (a) Typical SAXS patterns for hard carbon. Samples synthesized from cellulose at different temperatures. (b) Radius of gyration of hard carbon samples as a function of the temperature treatment and the relative pore number. Reprinted from Simone et al. (2016). Copyright (2016), with permission from Elsevier.

\subsubsection{Hard carbon surface chemistry}

Hard carbon surface chemistry plays an important role in sodium storage as the material surface will interact with the surrounding environment (electrolyte, $\mathrm{Na}^{+}$). At a molecular level, a high chemical reactivity is exhibited by the surface atoms as their atomic and electronic structure changes. For example, following the thermal treatment, hard carbons surface develops various chemical complexes (generally oxygen functional groups), which influence the electrochemical performance. As the hard carbons are obtained by heating the carbon precursor in a wide range of temperatures, the functional groups will vary as well. Presence of heteroatoms $(\mathrm{N}, \mathrm{S}, \mathrm{P}, \mathrm{H})$ and physisorbed water can also play an important role in both the maximum reversible capacity and the irreversible capacity. Besides heating temperature, precursor selection may also modify the surface chemistry. The most common techniques used to characterize hard carbon surface chemistry are TPD-MS, XPS and EDX. However, compared to the hard carbon structure and porosity investigations that are reported in most papers, the surface chemistry is less studied.

TPD-MS is an analysis method that investigates changes taking place on the bulk material when the temperature is varied in a controlled manner. TPD-MS is mainly used to identify the oxygen functional groups present on the hard carbon structure. During hard carbon heating, the functional groups are decomposed releasing $\mathrm{CO}, \mathrm{CO}_{2}, \mathrm{H}_{2} \mathrm{O}$ and $\mathrm{H}_{2}$ at temperatures corresponding to their thermal stability. Of high interest when analyzing hard carbons is also the amount of functional groups. Typically, $\mathrm{CO}$ can be derived from groups such as phenol, ether, carbonyl and quinone while $\mathrm{CO}_{2}$ is released as a result of acidic groups (carboxyl and/or anhydride groups) decomposition (Figure 3.10(a)). Only a few studies implying this characterization technique have been reported for hard carbons, although currently employed for activated porous carbons. As the annealing temperature increases, the amount of functional groups decreases, as shown in Figure 3.10. Zhang et al. (2016) showed such dependence of COx groups by thermally treating PAN carbon nanofibers at various temperatures ranged between 650 and $2,800^{\circ} \mathrm{C}$. A decrease in functional groups, amount from 0.6 to $0.01 \mathrm{mmol} \cdot \mathrm{g}^{-1}$, was reported as well for cellulose-derived hard carbons when increasing the temperature from 1,000 to $1,600^{\circ} \mathrm{C}$ (Matei Ghimbeu et al. 2018). 
Similar results were reported by Irisarri et al. when preparing hard carbons from phenolic resins, i.e., the oxygen functional groups decrease from $0.86 \mathrm{mmol}^{\circ} \mathrm{g}^{-1}$ at $1,200^{\circ} \mathrm{C}$ to $0.64 \mathrm{mmol}^{-1} \mathrm{~g}^{-1}$ at $1,500^{\circ} \mathrm{C}$. Besides temperature dependence, the oxygenated groups significantly vary with the precursor used as exposed in Figure 3.10(b).
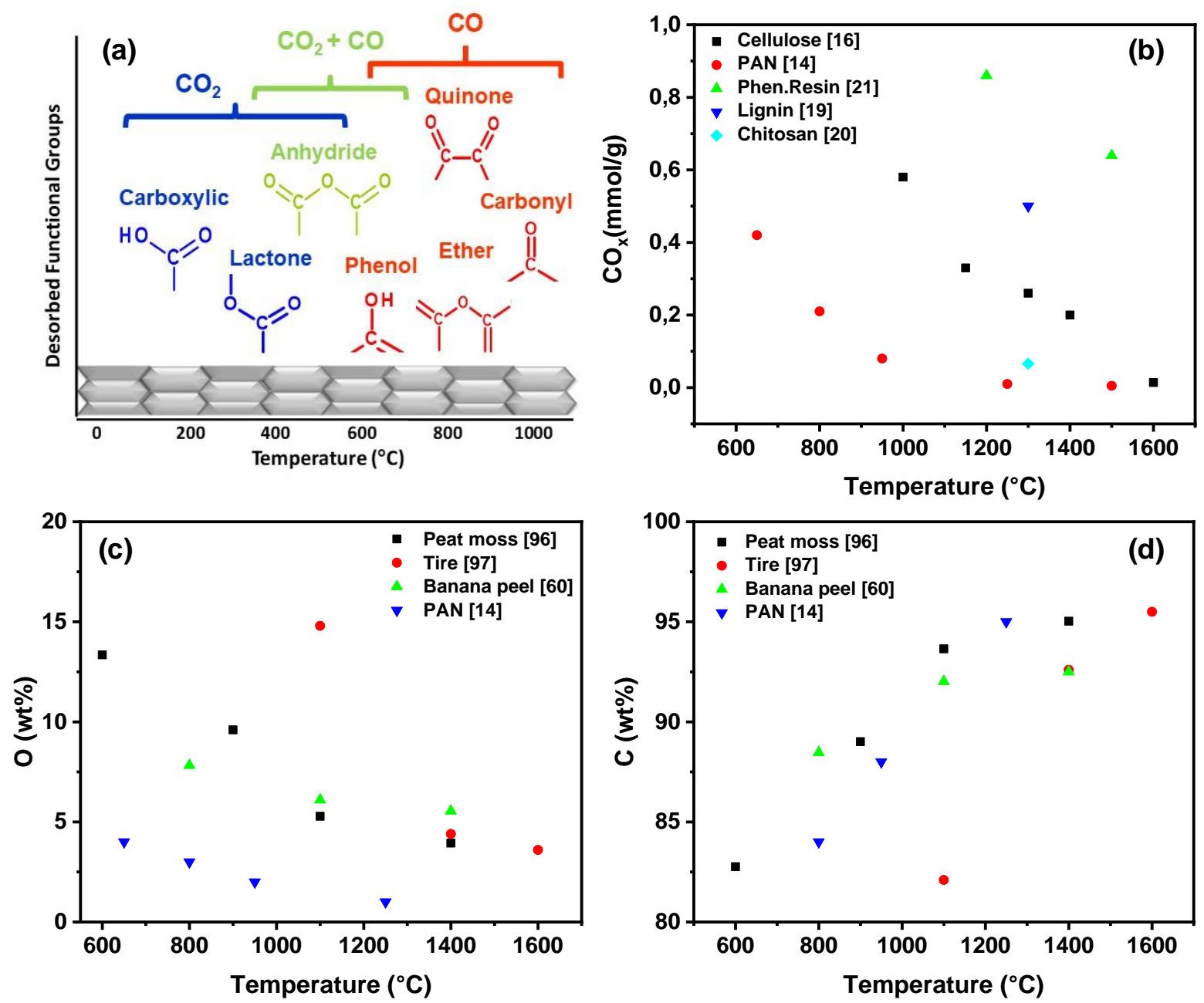

Figure 3.10. Schematic representation of oxygen-based functional groups evolving from carbon surface during thermal annealing (a). Evolution of total oxygen-based functional groups amount (COX) versus heating temperature of different precursors (PAN - Zhang et al. 2016; Phenolic resin - Irisarri et al. 2018; Cellulose - Matei Ghimbeu et al. 2018; Lignin Matei Ghimbeu et al. 2019; Chitosan - Conder et al. 2019). (c) Oxygen and (d) carbon content of hard carbon materials derived from different precursors as revealed by XPS (Peat moss Ding et al. 2013; Banana peel - Lotfabad et al. 2014; Tire - Li et al. 2016d; PAN - Zhang et al. 2016).

More insights on the surface chemical composition are provided by XPS (maximum 10 $\mathrm{nm}$ depth), a popular technique used to analyze hard carbons for providing valuable quantitative and chemical state information. The hybridization state in which carbon atoms are found (usually a mix of sp2 and sp3) and the percentage of different oxygen-based functional groups (COOR, C-OR, $\mathrm{C}=\mathrm{O}$, etc.) can be elucidated, likewise. Elements ( $\mathrm{S}, \mathrm{N}$, metals) bounded to carbon can be also identified. As the quantitative information is accurate, XPS results are often used to determine the $\mathrm{C}$ to $\mathrm{O}$ ratio. Figures 3.10(c) and (d) shows the $\mathrm{O}$ and $\mathrm{C}$ content evolution with annealing temperature of few selected hard carbon materials, derived from different 
precursors. It is well illustrated the temperature dependence of both $\mathrm{O}$ and $\mathrm{C}$ content: while the $\mathrm{O}$ amount decreases with the increase in pyrolysis temperature, the $\mathrm{C}$ content increases, as expected. Such tendency is observed for most of the hard carbon materials, however, for a given temperature both $\mathrm{O}$ and $\mathrm{C}$ content is highly dependent on precursor type, especially at low temperatures. For example, at $900^{\circ} \mathrm{C}$, the hard carbon made out of peat moss has $\sim 10 \mathrm{wt} \% \mathrm{O}$ content whereas PAN has only $2.5 \mathrm{wt} \%$.

Elemental analysis often used to get additional information on the bulk composition usually reveals similar trends as the XPS technique. However, when the materials contain impurities, their amount cannot be determined. In addition, the quantification of oxygen is not possible and is usually estimated by the difference $100 \%-\square \%$ (CNHS). In such case, EDX may provide information about the bulk composition and detect the presence of impurities. For example, in the case of biomass waste derived carbons, EDX is an important tool for such a purpose (Zhang et al. 2017c). For the doped hard carbons, EDX is often used to determine if the doping with heteroatoms was uniformly achieved (Hong et al. 2018). However, the technique is limited, especially for light elements such as $\mathrm{N}$ or B that are used as dopants. Therefore, depending on hard carbon nature, a pallet of complementary techniques is required to give a complete overview about the nature and quantity of functional groups, dopants or impurities constituting the material.

\subsubsection{Hard carbon structural defects}

As mentioned before, hard carbon structure consists of a mixture stacked graphene clusters randomly oriented and micropores. Depending on the annealing temperature, the materials present heteroatoms and/or impurities, therefore, the final hard carbon structure presents defects. Since it is impossible to prepare defect-free hard carbons, understanding their influence on the electrochemical performance is fundamental. There are several types of defects that could be accounted in the hard carbon structure: point defects (lattice mono- or divacancies), cluster defects (Stone-Wales defects) and boundaries or edges. Tsai et al. (2015) studied the effect of point and cluster defects on $\mathrm{Na}$ intercalation into disordered carbons by computational method. They pointed out that, the first $\mathrm{Na}^{+}$ion intercalated is stored close to the defect sites, as result of the strong binding energy ion-defect. In addition, it was also found that structural defects can enhance sodium intercalation, especially through mono- and di-vacancies while, in the case of Stone-Wales defects, the improvement is less significant.

Raman spectroscopy is widely used for characterizing the degree of order in carbon allotropes, and thus it is a powerful complement to XRD structural analysis. It consists of using an incident laser beam to generate light scattering from the studied sample (Inagaki and Kang 2016). Generally, visible light wavelengths are used, which only resonates with the $\pi$ electrons of sp2-hybridized carbons. Consequently, the obtained Raman spectrum does not provide direct information regarding sp3- hybridized carbons related to amorphous carbon allotropes (Ferreri and Robertson 2000; Dou et al. 2019). The Raman spectrum of hard carbon presents two main relative well-defined features, the $G$ and the $D$ band. The $G$ band located around 1,580 $\mathrm{cm}^{-1}$ is related to the in-plane vibrations of sp2 carbons, not only carbons in six-fold rings. The D band placed around $1,355 \mathrm{~cm}^{-1}$ is associated with the ring breathing modes that only become active in the presence of disorder, therefore, it is directly related to the presence of six-fold aromatic rings, and has no intensity for defects-free materials (Ferreri, Robertson 2000; Inagaki and Kang 2016; Bommier et al. 2018). As hard carbon structure combines disordered and graphitic domains, D-band has a high intensity and is proportional to the defect's concentration. The graphitic domains (crystalline graphite) are identified by the G-band. By determining the ratio 
between the area/intensities of $\mathrm{D}$ and $\mathrm{G}$ bands (ID/IG or IG/ID), the amount of defects (disorder degree) can be estimated. Figure 3.11(a) shows trends for the structural defects present in the hard carbon structure determined by both ID/IG and IG/ID ratios.
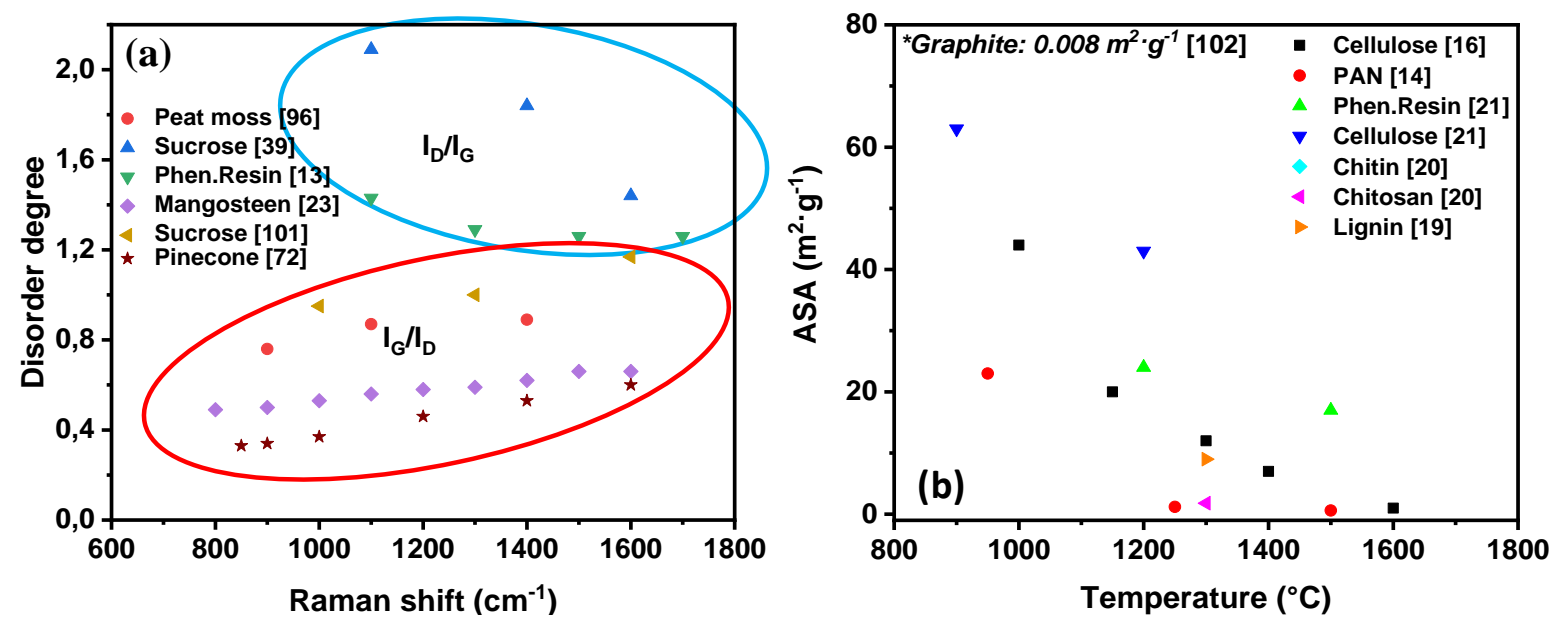

Figure 3.11. (a) Disorder degree determined by either the ID/IG or IG/ID ratio based on Raman spectroscopy. Evolution according to the pyrolysis temperature of different precursors reported in various studies (Peat moss - Ding et al. 2013; Sucrose - Bommier et al. 2014; Sucrose - Li et al. 2017b; Mangosteen - Wang et al. 2017; Pinecone - Zhang et al. 2017c; Phenolic resin - Beda et al. 2018). (b) Active surface area (carbon edges defects) of different hard carbon materials determined by TPDMS measurements (Graphite - Spahr et al. 2006; PAN - Zhang et al. 2016; Phenolic resin, Cellulose - Irisarri et al. 2018; Cellulose - Matei Ghimbeu et al. 2018; Lignin - Matei Ghimbeu et al. 2019; Chitin, Chitosan - Conder et al. 2019).

For hard carbon materials obtained from different precursor sources (raw biomass and polysaccharides), a decrease in the ID/IG ratio is observed with temperature increase indicating less structural defects and increase ordering. This phenomenon can be explained by the fact that at lower temperatures, all the graphene sheets are independent and thus only sp2 carbons are detected. However, when temperature increases, the graphene sheets get closer to each other and begin to align, but punctual defects are still created at the junction points. Consequently, sp3 carbons are detected and their intensity increases with temperature. When IG/ID value is taken into account, the trend is opposite, as expected. As for most of hard carbon characteristics, the disorder degree does not rely just on the heating temperature, precursor selection playing an important role (Figure 3.11(a)).

However, it has been pointed out that Raman does not take into consideration the defects caused by micropores $(<2 \mathrm{~nm})$ and moreover it is not quantitative. Therefore, TPD-MS can be used to determine the amount of defects including contribution of micropores. The active surface area (ASA) is correlated to all different types of defects present on the carbon edges such as stacking faults, single and multiple vacancies, and dislocations. Presence of such active sites is important since they can interact with other species (i.e. $\mathrm{Na}^{+}$). ASA is determined by $\mathrm{O} 2$ chemisorption on a vacuum-cleaned hard carbon and quantification of surface oxygenated complexes subsequently formed. The assessment of such parameter requires specific set-up which is not very common in literature and only a few studies have reported such values. The few works found (Figure 3.11(b)) show that the ASA values decrease with the increase in carbonization temperature for all precursors used, cellulose, PAN or phenolic resin, in line with the Raman results. At higher temperatures $\left(>1.700^{\circ} \mathrm{C}\right)$ a very low amount of defects is usually 
seen, no matter the precursor used. Moreover, the dependence on the precursor used is clear, e.g., $18 \mathrm{~m}^{2} \cdot \mathrm{g}^{-1}$ for phenolic resin vs. $\sim 0.5$ for PAN/cellulose at $1500^{\circ} \mathrm{C}$. Although most of the studies limit the temperature to $\sim 1600^{\circ} \mathrm{C}$ (to avoid a high degree of graphitization which hinders sodium storage), Zhang paper shows clearly that PAN derived hard carbons have very low ASA values in the temperature range of $1,500-2,800^{\circ} \mathrm{C}$. These values are comparable with those found for graphite (Spahr et al. 2006; Novák et al. 2007).

\subsection{Electrochemical performance}

\subsubsection{Materials performance}

Since the work of Stevens and Dahn (2000) on sodium insertion into hard carbon in 2000s, many groups had reported electrochemical performance of these materials in half coin cells configuration. Generally, specific capacities vary from 200 to $360 \mathrm{mAh} \cdot \mathrm{g}^{-1}$, depending on the hard carbon properties, such as their morphology, composition, porosity/specific surface area, microstructure, defects concentration, etc., which are deeply related to the synthesis parameters: precursor type, solvents, pretreatments, pyrolysis temperature, etc. The electrochemical performance also depends strongly on test conditions such as electrode mass, C-rate, cut-off voltage or the presence/absence of a potentiostatic step. Table 3.2 summarizes some electrochemical performance of different hard carbons at different cycling conditions.

Regarding polysaccharides precursors, glucose, sucrose and cellulose were employed and the best results in terms of first reversible capacities, for glucose derived hard carbon were obtained by Stevens and Dahn in 2000 (Stevens and Dahn 2000), i.e., $300 \mathrm{mAh} \cdot \mathrm{g}^{-1}$. For sucrose, $362 \mathrm{mAh} \cdot \mathrm{g}^{-1}$ was obtained by Qiu et al. (2017) at $20 \mathrm{~mA} \cdot \mathrm{g}-1$. The group of Palacin achieved capacities around $340 \mathrm{mAh} \cdot \mathrm{g}^{-1}$ at $2 \mathrm{C}$ rate with sucrose-derived carbon-coated materials cycled at high temperature $\left(75^{\circ} \mathrm{C}\right)$ (Ponrouch and Palacín 2015). For cellulose, the best reversible capacities were achieved by Komaba et al. (2017) ( $349 \mathrm{mAh}^{\cdot} \mathrm{g}^{-1}$ at $\left.25 \mathrm{~mA} \cdot \mathrm{g}^{-1}\right)$, Qiu et al. (2017) (324 $\mathrm{mAh} \cdot \mathrm{g}^{-1}$ at $\left.20 \mathrm{~mA} \cdot \mathrm{g}^{-1}\right)$ and Simone et al. (2016) (308 $\mathrm{mAh} \cdot \mathrm{g}^{-1}$ at $\left.37.2 \mathrm{mAh} \cdot \mathrm{g}^{-1}\right)$. In terms of raw biomass, $360 \mathrm{mAh} \cdot \mathrm{g}^{-1}$ were attained using Mapple leaf (Li et al. 2016a), $355 \mathrm{mAh} \cdot \mathrm{g}^{-1}$ employing banana peel (Lotfabad et al. 2014) and $329 \mathrm{mAh} \cdot \mathrm{g}^{-1}$ provided by mangosteen (Wang et al. 2017a). Finally, fossil resources (coal or petroleum) derived polymers have been also studied. The best results were obtained by Hasegawa et al. (2015) for phenolic resins, with up to $353 \mathrm{mAh} \cdot \mathrm{g}^{-1}$ specific capacity. For more exhaustive descriptions, the reader can refer to the review article of Saurel et al. (2018).

Hard carbon materials present very different electrochemical behavior at different synthesis conditions, especially at different pyrolysis temperatures, given the evolution of the microstructure and both open and closed porosity. Figure 3.12 shows the relation between the reversible capacity and the ICE with the annealing temperature for some HC-derived from different precursors. At low temperatures (below $1,000^{\circ} \mathrm{C}$ ), the hard carbons exhibit a low first reversible capacity $\left(<200 \mathrm{mAh} \cdot \mathrm{g}^{-1}\right)$ and low ICE $(<50 \%)$. With the augmentation of the annealing temperature, the graphitization degree of the hard carbon structure improves via the

removal of surface functional groups, defects concentration and porosity. In parallel, the specific surface area decreases, most pores close and creation of closed pores occur. Between $1,300^{\circ} \mathrm{C}$ and $1,600^{\circ} \mathrm{C}$, the reversible capacity improves significantly reaching values over 350 mAh.g ${ }^{-1}$ while the ICE increases to around $80 \%$, respectively, for some of the precursors. The specific mechanism behind sodium uptake by different structure is still under debate, as seen in the next part of the chapter. However, it is clear that hard carbons synthesized between 1,300 and $1,600^{\circ} \mathrm{C}$ present in general the best performance. 
Higher annealing temperatures $\left(>1,600^{\circ} \mathrm{C}\right)$ lead to a more organized structure in which the sodium uptake is limited, as can be seen from the decrease of the first reversible capacities recorded for all the given precursors in Figure 3.12. In addition, the rate capability of hard carbon materials is of great importance, which is rather poor, compared to graphite and soft carbon capabilities ( $\mathrm{Li}$ et al. 2014; Saurel et al. 2018), and decreases with annealing temperature, as can be seen from the values listed in Table 3.2.

Table 3.2. Electrochemical performance of different $H C$ reported in literature

\begin{tabular}{|c|c|c|c|c|c|c|c|}
\hline Precursor & $\begin{array}{c}\mathbf{T} \\
\left({ }^{\circ} \mathbf{C}\right)\end{array}$ & $\begin{array}{l}\text { ICE } \\
(\%)\end{array}$ & $\begin{array}{l}\text { Total Cap. } \\
\left(\mathbf{m A h} \cdot g^{-1}\right)\end{array}$ & $\begin{array}{l}\text { Rev. Cap. } \\
\left(\mathbf{m A h} \cdot \mathbf{g}^{-1}\right)\end{array}$ & $\begin{array}{c}\text { C-rate } \\
\left(\mathbf{m A} \cdot \mathbf{g}^{-1}\right)\end{array}$ & $\begin{array}{l}\text { Capacity } \\
\text { retention }\end{array}$ & Ref. \\
\hline Pitch/phenolic resin (1:1) & 1400 & 86 & 301 & 259 & $\begin{array}{c}30 \\
(0.1 \mathrm{C}) \\
\end{array}$ & $\begin{array}{c}94 \% \text { in } 100 \\
\text { cycles }\end{array}$ & {$[25]$} \\
\hline Pitch/phenolic resin (1:1) & 1600 & 84 & 250 & 210 & $\begin{array}{c}30 \\
(0.1 \mathrm{C}) \\
\end{array}$ & $\begin{array}{c}90 \% \text { in } 100 \\
\text { cycles }\end{array}$ & {$[25]$} \\
\hline $\begin{array}{c}\text { Phenol/formaldehyde } \\
\text { resin }\end{array}$ & 1250 & 60 & 517 & 311 & 20 & $\begin{array}{l}>80 \% \text { in } \\
100 \text { cycles }\end{array}$ & {$[24]$} \\
\hline $\begin{array}{c}\text { Resorcinol/formaldehyde } \\
\text { resin } \\
\end{array}$ & 1600 & 95 & 368 & 350 & 20 & $\begin{array}{c}94 \% \text { in } 100 \\
\text { cycles }\end{array}$ & [26] \\
\hline $\begin{array}{l}\text { Phloroglucinol/glyoxylic } \\
\text { acid resin }\end{array}$ & 1300 & 76 & 355 & 270 & 37.2 & $\begin{array}{c}92 \% \text { in } 100 \\
\text { cycles }\end{array}$ & [13] \\
\hline Glucose & 1100 & 88 & 349 & 307 & $33 *$ & N/A & [104] \\
\hline Sucrose (coated) & 1000 & 83 & 335 & 279 & $\begin{array}{c}30 \\
(0.1 \mathrm{C}) \\
\end{array}$ & $\begin{array}{c}80 \% \text { in } 100 \\
\text { cycles }\end{array}$ & [109] \\
\hline Sucrose (coated) & 1600 & 84 & 381 & 320 & $\begin{array}{c}30 \\
(0.1 \mathrm{C}) \\
\end{array}$ & $\begin{array}{c}93 \% \text { in } 100 \\
\text { cycles }\end{array}$ & [109] \\
\hline Cellulose & 1400 & 83 & 375 & 310 & 37.2 & $\begin{array}{c}90 \% \text { in } 200 \\
\text { cycles }\end{array}$ & [92] \\
\hline Cellulose & 1600 & 84 & 366 & 307 & 37.2 & $\begin{array}{c}94 \% \text { in } 200 \\
\text { cycles }\end{array}$ & [92] \\
\hline Mangosteen Shell & 1500 & 83 & 396 & 329 & $\begin{array}{c}20 \\
(0.1 \mathrm{C})\end{array}$ & $\begin{array}{c}98 \% \text { in } 100 \\
\text { cycles }\end{array}$ & {$[23]$} \\
\hline Lotus stem & 1400 & 70 & 501 & 351 & 40 & $\begin{array}{c}94 \% \text { in } 450 \\
\text { cycles (at } \\
\left.100 \mathrm{~mA} \cdot \mathrm{g}^{-1}\right)\end{array}$ & [71] \\
\hline Apple waste & 1100 & 61 & 400 & 245 & $\begin{array}{c}4 \\
(0.02 \mathrm{C})\end{array}$ & $\begin{array}{c}100 \% \text { in } 80 \\
\text { cycles (at } 20 \\
\left.\mathrm{~mA} \cdot \mathrm{g}^{-1}\right)\end{array}$ & {$[54]$} \\
\hline $\begin{array}{c}\text { Apple pomace - pectin } \\
\text { free }\end{array}$ & 1100 & 66 & 450 & 297 & $\begin{array}{c}20 \\
(0.1 \mathrm{C}) \\
\end{array}$ & $\begin{array}{c}96 \% \text { in } 230 \\
\text { cycles }\end{array}$ & [93] \\
\hline $\begin{array}{l}\text { Banana Peel } \\
\text { (activated) }\end{array}$ & 1100 & 78 & 455 & 355 & 0.05 & $\begin{array}{c}88 \% \text { in } 300 \\
\text { cycles (at } \\
\left.0.1 \mathrm{~A} \cdot \mathrm{g}^{-1}\right)\end{array}$ & [108] \\
\hline
\end{tabular}

* $\mu \mathrm{A} . \mathrm{cm}^{-2}$ 

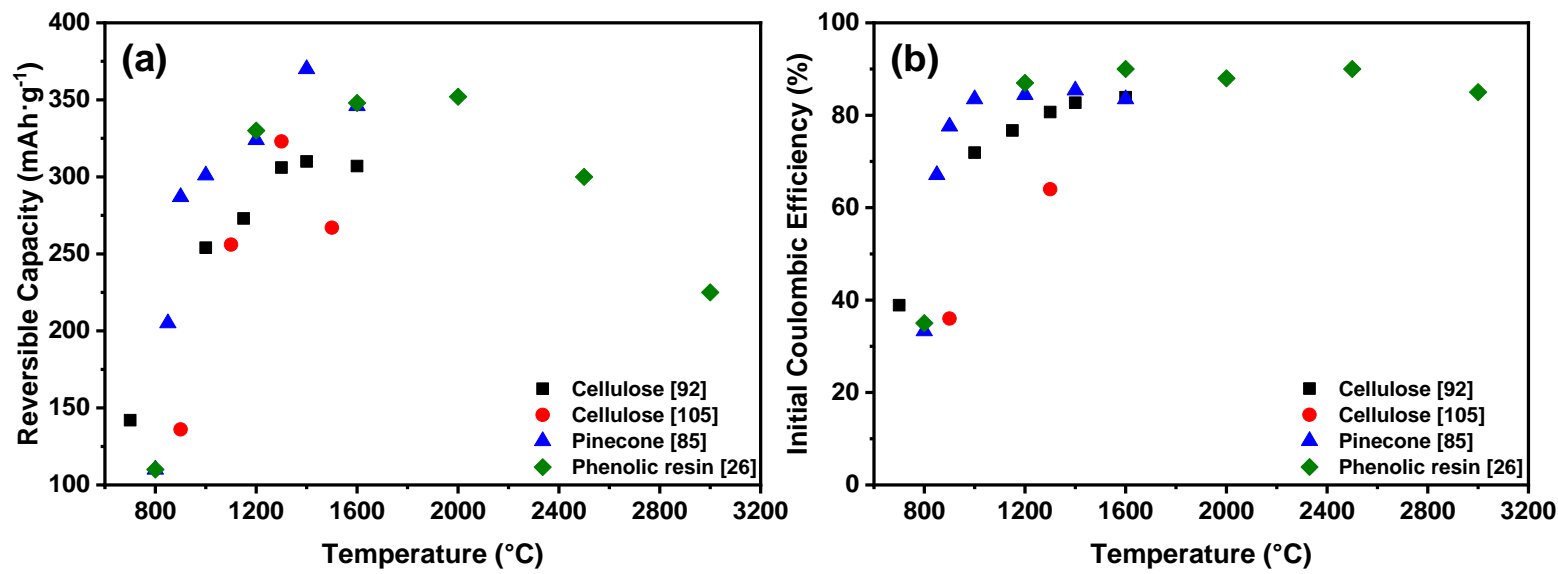

Figure 3.12. (a) Reversible capacity and (b) ICE of different hard carbons as a function of pyrolysis temperature: cellulose (Simone et al. 2016), cellulose (Qiu et al. 2017), Pinecone (Zhang et al. 2017c), phenolic resin (Hasegawa et al. 2015).

Open porosity represents a key feature regarding the electrochemical behavior of hard carbon. Bommier et al. (2014) intensely studied the relationship between the open porosity and the final reversible capacity. By using sucrose derived hard carbon, an inverse proportionality was found between the pore volume and the developed surface area with the final reversible capacity.
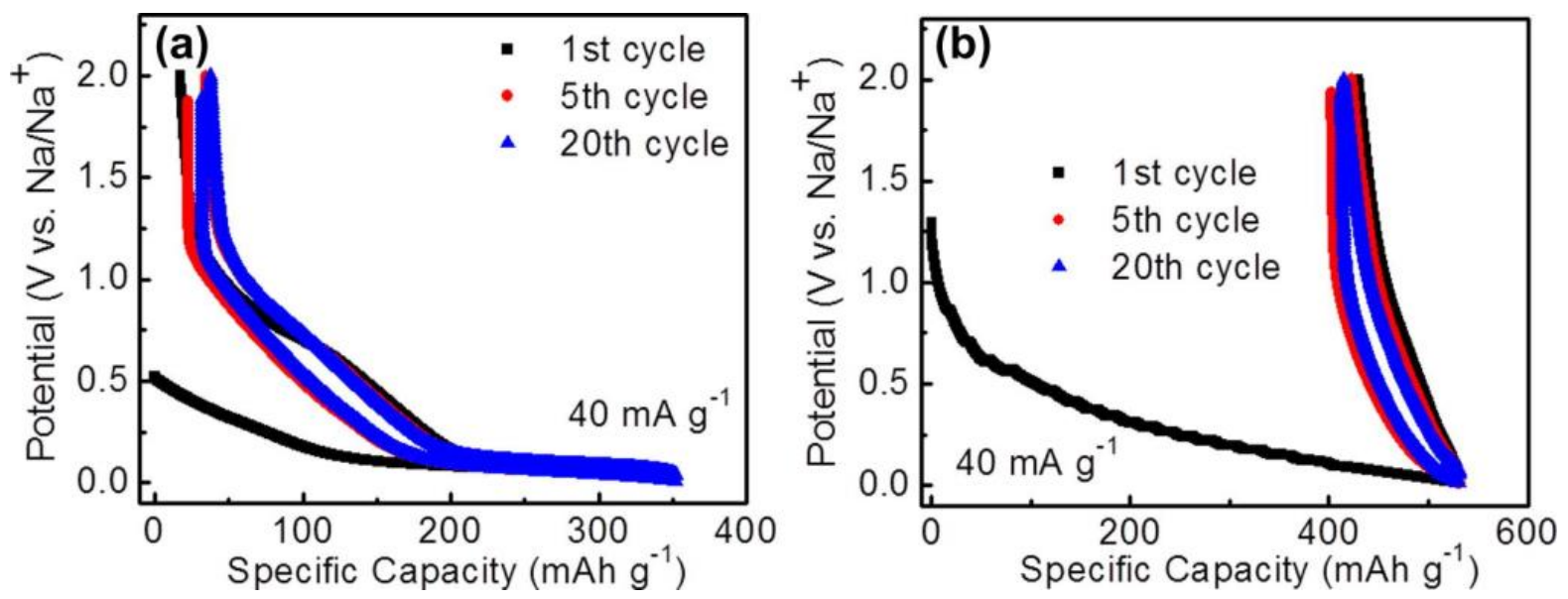

Figure 3.13. Charge/discharge profiles for (a) low surface area hard carbon and (b) high surface area hard carbon. Reprinted from Bommier et al. (2014). Reprinted from Bommier et al. (2014). Copyright (2014), with permission from Elsevier.

Interestingly, very high surface area hard carbons $\left(>1,000 \mathrm{~m}^{2} \cdot \mathrm{g}^{-1}\right)$ present very different charge/discharge profiles than lower surface area carbons, as can be seen from Figure 3.13. Qiu et al. (2017) found similar results using a template hard carbon produced from phenolic resin. Both works argue that at very high surface area values, an important capacitive contribution takes place. The electrolyte's decomposition increases significantly and the volume of carbon for storing $\mathrm{Na}$ ions is drastically reduced. 
The morphology of the final hard carbon also influences its performance. Although most precursors result in random-like morphology, spherical particles obtained by HTC of carbohydrates or polymerization of phenolic resins as well as fiber-like materials made by electrospinning were reported. Hard carbon hollow nanospheres were obtained by Tang et al. (2012) using latex templates and glucose. The initial reversible capacity and ICE were 223 $\mathrm{mAh} \cdot \mathrm{g}^{-1}$ (at $40 \mathrm{~mA} \cdot \mathrm{g}^{-1}$ ) and $42 \%$, respectively. However, this carbon is able to retain approximately $88 \%$ of the initial capacity after 100 cycles at $100 \mathrm{~mA} \cdot \mathrm{g}^{-1}$ cycling rate and 50 $\mathrm{mAh} \cdot \mathrm{g}^{-1}$ at $10 \mathrm{~A} \cdot \mathrm{g}^{-1}$, showing an outstanding rate capability. Hollow spheres were also obtained from pollen grains, as presented before, taking advantage of the natural occurring morphology of this precursor. Sucrose-derived microspheres were synthesized by Qiu et al. (2017) obtaining a significantly high reversible capacity of $362 \mathrm{mAh} \cdot \mathrm{g}^{-1}$ and $86 \%$ of columbic efficiency. Regarding fiber-like morphologies, Bai et al. (2015) studied the influence of the fiber morphology on the electrochemical performance of the hard carbon. They prepared PVC nanofibers by electrospinning and further pyrolyzed them at $700^{\circ} \mathrm{C}$. Results showed that the PVC nanofibers had better performance than PVC particles (reference hard carbon). A reversible capacity of $271 \mathrm{mAh} \cdot \mathrm{g}^{-1}$ was obtained at $12 \mathrm{~mA} \cdot \mathrm{g}^{-1}, 70 \%$ of ICE, $79 \%$ retention rate after 120 cycles and $147 \mathrm{mAh} \cdot \mathrm{g}^{-1}$ at $240 \mathrm{~mA} \cdot \mathrm{g}^{-1}$ of cycling rate. PVC particles delivered only $206 \mathrm{mAh} \cdot \mathrm{g}^{-1}$ of reversible capacity at $12 \mathrm{~mA} \cdot \mathrm{g}^{-1}, 61 \%$ of ICE and $61 \%$ retention after 120 cycles. At this point, however, it is difficult to analyze the real impact of the carbon morphology on the electrochemical performances because it is a parameter difficult to change while maintaining the other characteristics as constant. More systematic studies are required in this direction.
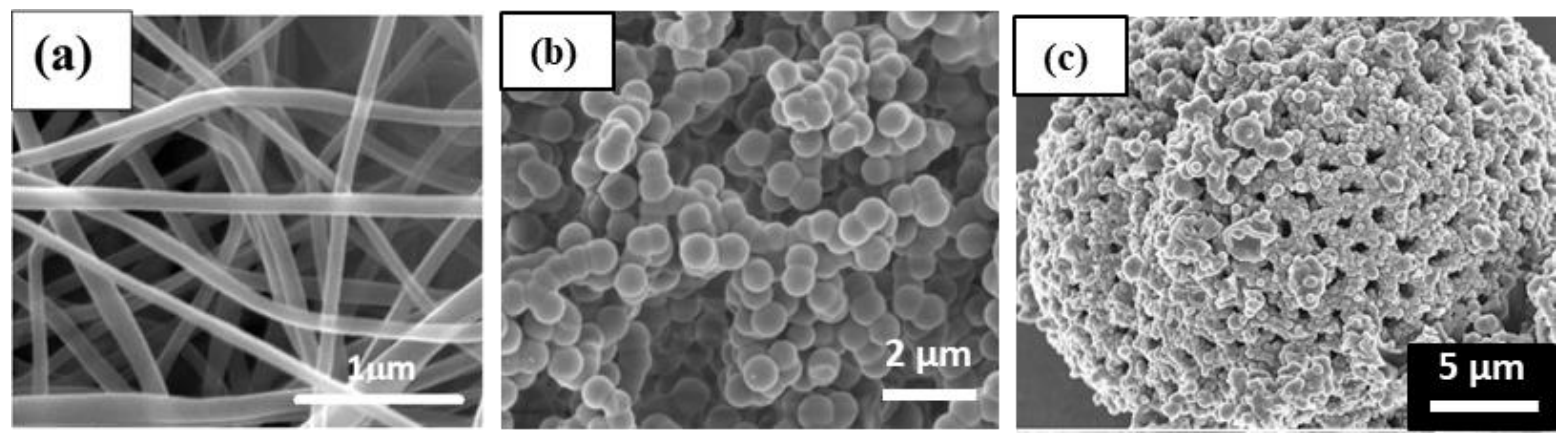

Figure 3.14. SEM images of (a) PVC nanofibers (Reprinted with permission from Bai et al. 2015 Copyright (2015) American Chemical Society), (b) hard carbon microspheres (Reprinted from Tang et al. 2012, Copyright (2012) with permission from Wiley \& Sons, Inc.) and (c) hollow reticulate hard carbon from pollen grains (Reprinted from Li et al. 2017a, Copyright (2017), with permission from Elsevier).

\subsubsection{Full Na-ion system performance}

As already mentioned, hard carbon is the most promising negative material for Na-ion application in terms of capacity, cycling behavior and power rate capability. From this point of view, almost all full Na-ion systems tests reported use hard carbons as negative electrode. However, few examples have been reported so far. Moreover, comparing performance is rather complicated as capacities/energy densities are sometimes reported as a function of positive, negative, full active mass or full system. These systems used both transition metal oxide and polyanionic positive electrodes, which complicates the comparison. 
In 2011, Komaba's group showed results on coin-cell based NaNi0.5Mn0.5O2/hard carbon systems. They reported around $200 \mathrm{mAh} \cdot \mathrm{g}^{-1}$ (hard carbon mass) (Komaba et al. 2011). Later, Johnson et al. (2012) and Ponrouch et al. (2013) proposed, respectively, $\mathrm{NaNi}_{1 / 3} \mathrm{Mn}_{1 / 3} \mathrm{Co}_{1 / 3} /$ hard carbon and $\mathrm{Na}_{3} \mathrm{~V}_{2}\left(\mathrm{PO}_{4}\right)_{2} \mathrm{~F}_{3} /$ hard carbon systems. This last system showed a capacity of $100 \mathrm{mAh} \cdot \mathrm{g}^{-1}$ and very good performance in terms of cycling life and power rate capability. Zhang et al. (2016) prepared a full Na-ion using a PAN-derived CNF anode and $\mathrm{Na}_{2} \mathrm{Fe}_{2}\left(\mathrm{SO}_{4}\right)_{3}$ as the cathode and achieved $70 \mathrm{mAh} \cdot \mathrm{g}^{-1}$ of capacity (based on the cathode weight).

More recently, several proofs of concept have been established using "real" Na-ion cell formats such as prismatic or stacked pouch cells (Faradion n.d.) and 18,650 cylindrical cells (CNRS News 2015; Broux et al. 2019). Broux et al. (2019) showed impressive results in terms of cycling behavior (20\% capacity loss after almost 4,000 cycles at $1 \mathrm{C}$ and $100 \%$ depth of discharge) and rate capability (75\% capacity retention at $100 \mathrm{C}$ in discharge and at $10 \mathrm{C}$ in charge) for the system $\mathrm{Na}_{3} \mathrm{~V}_{2}\left(\mathrm{PO}_{4}\right)_{2} \mathrm{~F}_{3}$.
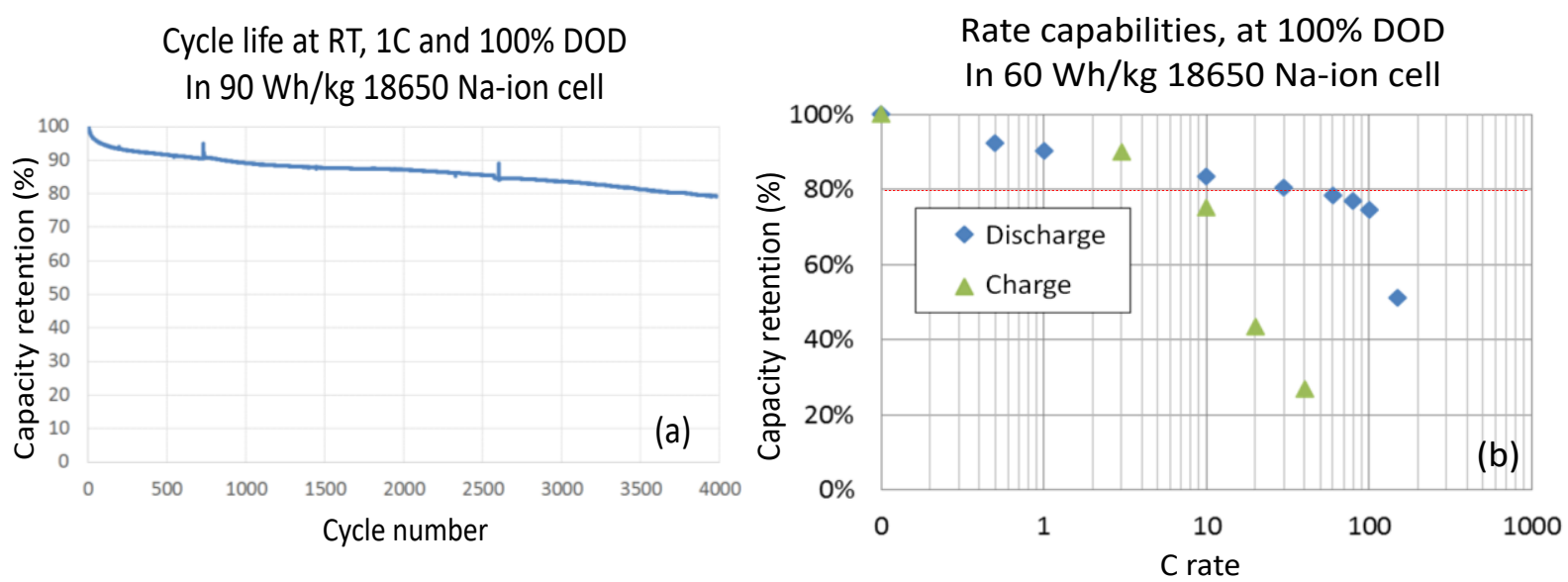

Figure 3.15. Performance obtained in 18,650 cells: (a) long-term cyclability at a 1 C rate upon charge and discharge for a $75 \mathrm{Wh} \mathrm{kg}-1$ prototypes and (b) rate capabilities for $55 \mathrm{Wh} \mathrm{kg}-1$ prototypes (Reprinted with permission from Broux et al. 2019 Copyright (2019) to John Wiley \& Sons, Inc.).

Demonstrations of integration in real systems have also been presented. FARADION first demonstrated integration in an E-bike (En ligneGreen Car Congress n.d.). The French network of Electrochemical Storage (RS2E) integrated it into a remote military robot (Ministère des Armées n.d.) and RS2E-spin off company TIAMAT presented a Na-ion powered electric scooter (Industrie-techno 2018). Very recently, the Chinese Na-ion battery company HiNa demonstrated the integration in a small electric vehicle (HiNa Battery Technology Co., Ltd n.d.).

\subsubsection{Sodium insertion mechanisms in hard carbon}

Although hard carbon development is an important issue to obtain competing materials for future energy storage systems, the fundamental understanding of the sodium storage mechanisms in hard carbon is a key aspect in order to design sustainable high-performing anodes for NIBs.

The early description of a Na-based charge storage mechanism in hard carbon was reported in the 2000s by Stevens and Dahn $(2000,2001)$ using the "falling cards" structural model. They proposed, based on XRD and SAXS analyses, that sodium is inserted in the carbon 
structure via a similar mechanism as for lithium, implying a two-stage "insertion-adsorption" process. The $\mathrm{Na}$ is first intercalated between the "pseudo-graphitic" nanodomains at high potentials $(>0.1 \mathrm{~V})$, giving rise to a slope potential region while at much lower potentials $(<0.1 \mathrm{~V})$, sodium is adsorbed in the carbon micropores, resulting in a plateau region. Since this pioneering work, several other works confirmed this mechanism (Alcántara et al. 2005; Gotoh et al. 2013; Irisarri et al. 2015; Simone et al. 2016), as schematically illustrated in Figure 3.16.
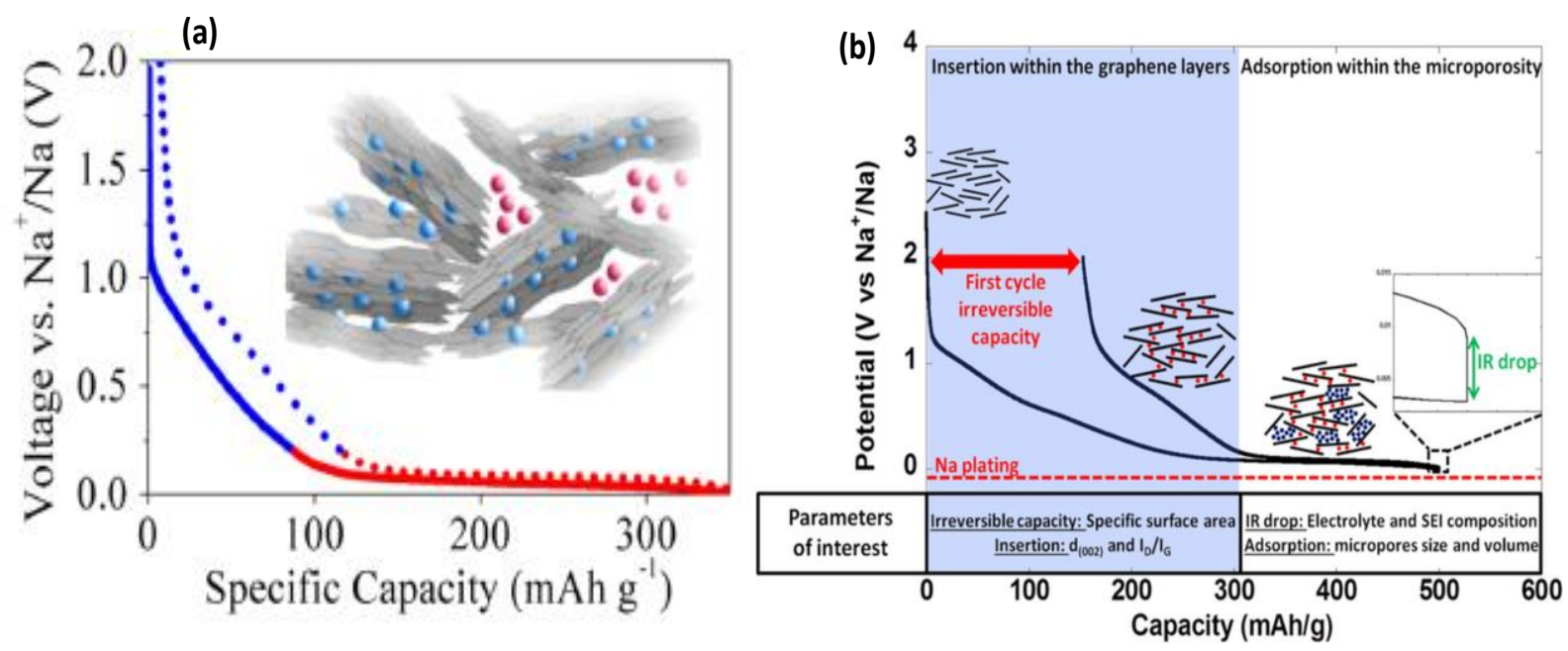

Figure 3.16. Visual representation of the card-house model on Na-ion storage in hard carbon showing the two distinct phases: intercalation between the graphitic domains and pore filling (Reprinted with permission from Bommier et al. 2015, Copyright (2015) to American Chemical Society). (b) Potential versus capacity profile for hard carbon when tested against sodium metal counter electrodes. The different steps of the mechanism are also labeled. Reprinted from Irisarri et al. (2015).

However, starting to the mid-2010s, the researcher's experimental observations could no longer rely on the "insertion-adsorption" mechanism. Therefore, different propositions of mechanisms have been postulated and to date, there is still no consensus about a general sodium ion mechanism in hard carbons. This is mainly related to the complexity of hard carbon structure and to several factors that are still not well understood, as proposed by Saurel et al. (2018): (1) the lack of knowledge regarding the accessibility of the electrolyte in the microporosity and precise characterization of porosity (open vs. closed porosity); (2) the contradictory structural results determined by both local (HR-TEM, Raman) and averaging (XRD) techniques induced by the inhomogeneous nature of hard carbon and (3) the wide range of susceptible mechanisms and their possible overlapping along with the missing combined characterization techniques, which would allow to confirm/infirm the intercalation mechanism (XRD, Raman) and/or micropore filling mechanism (SAXS, NMR). We would add here a fourth point, that is the theoretical and modeling works, which are limited and certainly could contribute to understanding such complex mechanisms.

Taking into consideration these aspects, the more recent proposed mechanisms will be described. Cao et al. (2012) studied the insertion of sodium in hallow carbon nanowires and they first ascribe the low potential region $(0.2-0 \mathrm{~V})$ to the intercalation of sodium between the graphitic layers by similitude with the behavior observed on lithium insertion into graphite. They suggest that the sloping region $(1-0.2 \mathrm{~V})$ might be related to the charge transfer on the surface of graphitic micro-domains. Theoretical calculations were undertaken as well and revealed that a graphitic interlayer space larger than $0.37 \mathrm{~nm}$ is required for sodium insertion/extraction. This value represents a balance between the attractive van der Waals 
interactions between the carbon layers and the repulsive interactions between the carbon layers and the Na ions. Later in 2013, Ding et al. (2013) prepared hard carbon at various annealing temperatures and observed that the interlayer space and the microporosity decreases while the graphitization in the materials increases. They noticed that the capacity gained in the plateau region increases with the increase in the temperature and they assigned this observation to the insertion of sodium between the graphitic layers rather than to the adsorption in the porosity. To sustain their hypothesis, the authors synthesized highly microporous carbon that revealed no potential plateau in the low voltage region, therefore excluding adsorption of $\mathrm{Na}$ in this region. Moreover, ex situ XRD studies showed a reversible shift of the (002) peak toward lower 2 theta values in the low potential region. All these observations strengthened the idea that the low potential plateau is related to Na intercalation between graphitic plans and not to the sodium adsorption in the porosity. Further works sustained this mechanism based on similar XRD observations (Komaba et al. 2011; Lotfabad et al. 2014).
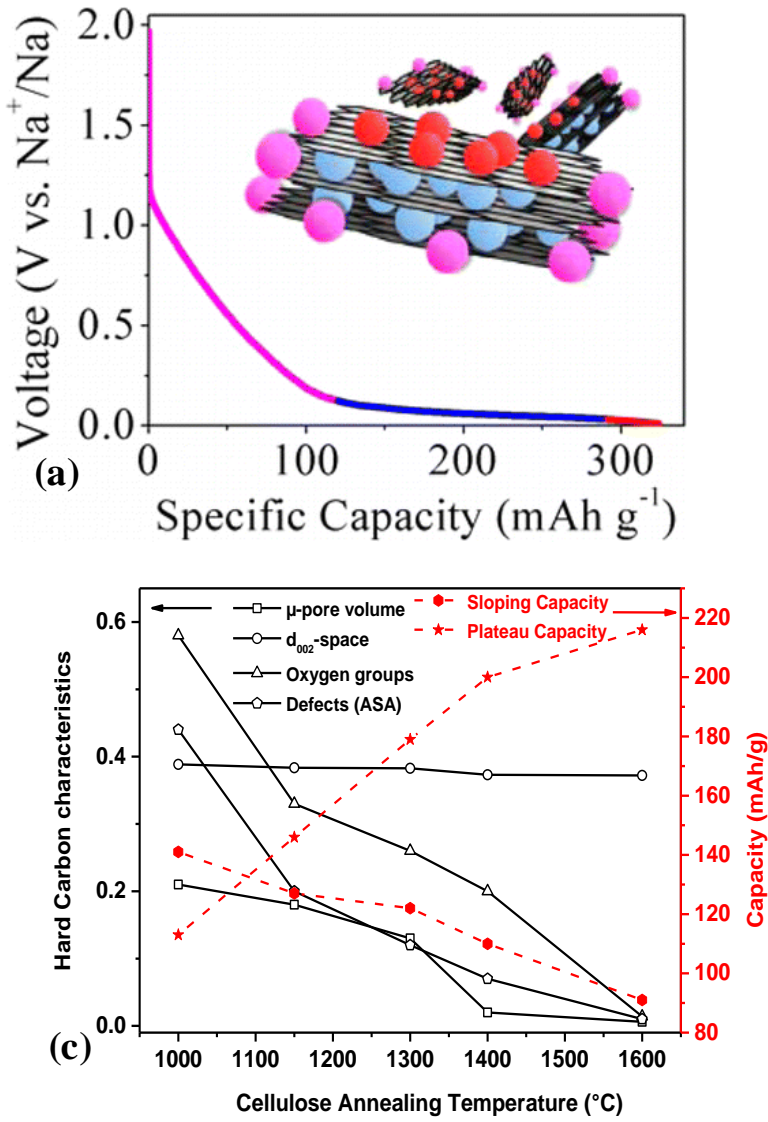
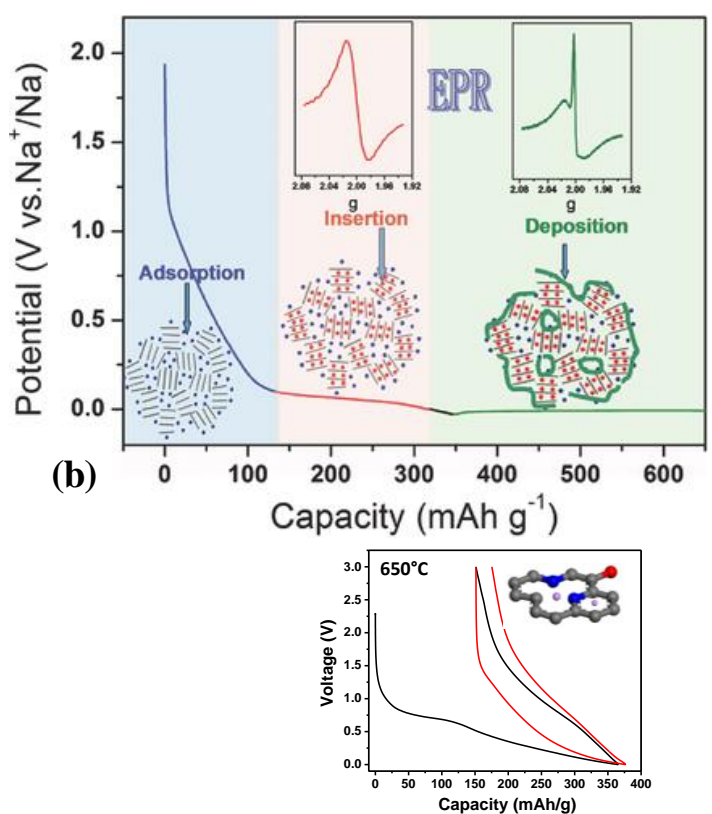

(d)

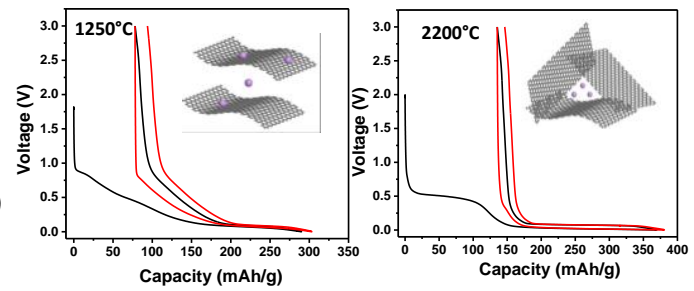

Figure 3.17. Representation of different storage mechanisms in hard carbons. (a) Potentiogram along with simplified representation of three stage storage mechanism (slope region: defect sites; plateau region: intercalation between graphite shits and small contribution of $\mathrm{Na}$ adsorption on pore surface) (Reprinted with permission from Bommier et al. 2015, Copyright (2015) to American Chemical Society); (b) "adsorption-insertion" mechanism involving adsorption on defect sites, insertion between the graphitic planes and Na deposition (Reprinted with permission from Qiu et al. 2017, Copyright (2017) to John Wiley \& Sons, Inc.); (c) correlation between the slope/plateau capacities and HC characteristics versus annealing temperature (Reprinted from Matei Ghimbeu et al. 2018, Copyright (2018), with permission from Elsevier) and (d) three-stage mechanism involving adsorption-insertion-filling depending on the pyrolysis temperature (Reprinted with permission from Zhang et al. 2016, Copyright (2016) to John Wiley \& Sons, Inc. 
In 2015, Bommier et al. (2015) pointed out another carbon characteristic that may be involved in the Na storage, namely the carbon defects. The authors evidenced a linear decrease in carbon defects expressed as ID/IG report (when increasing the pyrolysis temperature) and the sloping capacity. In consequence, they assign the sloping region to the $\mathrm{Na}$ interaction with the carbon defect sites. Based on XRD analyses, they further confirm the insertion of the sodium in the plateau region and in minor extent to the adsorption of $\mathrm{Na}$ on the pore surface (Figure 3.17(a)). Qiu et al. (2017) performed a systematic work on the characterization of hard carbons obtained at different temperature and employed in situ XRD and ex situ NMR techniques along with computational simulations, which allowed to propose an "adsorption-intercalation" mechanism of $\mathrm{Na}$ in hard carbon, (Figure 3.17(b)). Other works (Zhang et al. 2016; Matei Ghimbeu et al. 2018) suggested in addition, an impact coming from the carbon surface chemistry (oxygen-containing functional groups and heteroatoms) in the slope region.

Matei Ghimbeu et al. (2018) attempted to discriminate the contribution of oxygen surface groups, porosity and defects (Figure 3.17(c)). They first pointed out the importance of using complementary gases such as $\mathrm{CO}_{2}$ to assess correctly the porosity of hard carbons since carbons estimated "non-porous" based on $\mathrm{N}_{2}$ adsorption may present large amounts of small pores, ultamicropores $(<0.7 \mathrm{~nm})$. The authors also quantified the structural defects as active surface sites (ASA) and they observed that the increase in the pyrolysis temperature of cellulose triggers a decrease in the functional group amount, defects and porosity, which is accompanied by the reduction of the slope region capacity. In addition, the plateau capacity was observed to increase with the interlayer distance decrease. These results allowed them to assign the slope capacity to the insertion of sodium in the porosity and to the interactions with the defects, while the plateau region to the intercalation of sodium between the graphitic layers. Therefore, all these works listed above sustain rather an "adsorption-intercalation" mechanism.

Zhang et al. (2016) proposed a supplementary mechanism based on $\mathrm{Na}$ filling in the graphitic nanopores formed on hard carbons derived from PAN fibers, heated up to very high temperatures, i.e., 2,000 to $2,800^{\circ} \mathrm{C}$. This temperature range extension allowed them to observe for the first time a single plateau region with no contribution from the slope region. Depending on the annealing temperature, a three-stage insertion mechanism "adsorption-intercalationfilling" has been proposed (Figure 3.17(d)).

\subsection{Conclusion}

We have shown in this chapter that hard carbon materials derived from cheap, available and bio-sourced precursors can be successfully synthesized by simple pyrolysis process. Their main characteristics (porosity, structure, surface chemistry and defects) can be easily tuned by varying the precursor type and the processing conditions. Mainly, the precursors and the annealing temperature, are varied in most of the works and generally, for all precursors, the carbon characteristics decreases with the increase of the temperature, although for a given temperature the precursors have an impact as well. Even less studied, the chemical synthesis parameters also contribute to the diversity of hard carbon features.

Regarding the hard carbon properties, there are still challenges to determining the structure and porosity of such materials due to their low crystallinity and porosity. A panel of techniques must be used to correctly asses them. The use of nitrogen adsorption should be systematically combined with $\mathrm{CO}_{2}$ adsorption and SAXS measurements to better determine the open and closed porosity. The contribution of ultra-micropores and closed pores to $\mathrm{Na}$ storage/deposition is not yet well understood and requires further understanding. Regarding the surface chemistry (functional groups, dopants, inorganic impurities, etc.), it was found to be less studied than the porosity and structure, as well as its impact on the performance. Moreover, 
defects are rarely quantified, although theoretical and experimental studies suggest an important role in the Na storage.

Coming to the electrochemical performance, interplaying characteristics (small surface area, large d-space, presence of defects and functional groups) must be carefully balanced in order to reach satisfactory performance. Most electrochemical tests are performed in half-cell and several materials reached reasonable capacity close to $\sim 300 \mathrm{mAh} \cdot \mathrm{g}^{-1}$ at a $\mathrm{C} / 10$ rate. However, there is still a need for more in-depth studies to be undertaken, to evaluate the longterm cycling behavior, capacity retention at variable $\mathrm{C}$ rates and the behavior at different temperature. In addition, the optimization of carbon electrode and electrolyte formulations, of the electrochemical conditions that are less studied, would certainly lead to performance improvement.

Comprehensible studies of SEI formation and the parameters leading to its control must be still approached. Understanding the storage mechanism is still required and difficulty arises due to the complex carbon structure, which is challenging to assess along with limitations of in situ and ex situ postmortem techniques. The evaluation of hard carbons in full batteries is rarely considered, and represents an important point to be addressed in order to assess complete overall performance in real systems and to favor up-scaling and commercialization.

\subsection{References}

Alcántara, R., Lavela, P., Ortiz, G.F., and Tirado, J.L. (2005). Carbon microspheres obtained from resorcinol-formaldehyde as high-capacity electrodes for sodium-ion batteries. Electrochemical and Solid-State Letters, 8(4), A222-A225.

Anca-Couce, A. (2016). Reaction mechanisms and multi-scale modelling of lignocellulosic biomass pyrolysis. Progress in Energy and Combustion Science, 53, 41-79.

Bai, Y., Wang, Z., Wu, C., Xu, R., Wu, F., Liu, Y., Li, H., Li, Y., Lu, J., and Amine, K. (2015). Hard carbon originated from polyvinyl chloride nanofibers as highperformance anode material for Na-ion battery. ACS Applied Materials \& Interfaces, 7(9), 5598-5604.

Beda, A., Taberna, P.-L., Simon, P., and Matei Ghimbeu, C. (2018). Hard carbons derived from green phenolic resins for Na-ion batteries. Carbon, 139, 248-257.

Bommier, C., Luo, W., Gao, W.-Y., Greaney, A., Ma, S., and Ji, X. (2014). Predicting capacity of hard carbon anodes in sodium-ion batteries using porosity measurements. Carbon, 76, 165-174.

Bommier, C., Mitlin, D., and Ji, X. (2018). Internal structure-Na storage mechanismsElectrochemical performance relations in carbons. Progress in Materials Science, 97, 170-203.

Bommier, C., Surta, T.W., Dolgos, M., and Ji, X. (2015). New mechanistic insights on Na-ion storage in nongraphitizable carbon. Nano Letters, 15(9), 5888-5892.

Broux, T., Fauth, F., Hall, N., Chatillon, Y., Bianchini, M., Bamine, T., Leriche, J.-B., Suard, E., Carlier, D., Reynier, Y., Simonin, L., Masquelier, C., and Croguennec, L. (2019). High rate performance for carbon-coated Na3V2(PO4)2F3 in Na-ion batteries. Small Methods, 3(4), 1800215.

Buiel, E.R., George, A.E., and Dahn, J.R. (1999). Model of micropore closure in hard carbon prepared from sucrose. Carbon, 37(9), 1399-1407.

Cao, L., Hui, W., Xu, Z., Huang, J., Zheng, P., Li, J., and Sun, Q. (2017). Rape seed shuck derived-lamellar hard carbon as anodes for sodium-ion batteries. Journal of Alloys and Compounds, 695(Supplement C), 632-637.

Cao, Y., Xiao, L., Sushko, M.L., Wang, W., Schwenzer, B., Xiao, J., Nie, Z., Saraf, L.V., 
Yang, Z., and Liu, J. (2012). Sodium ion insertion in hollow carbon nanowires for battery applications. Nano Letters, 12(7), 3783-3787.

CNRS News. (2015). A battery revolution in motion. [Online]. Available at: https://news.cnrs. fr/articles/a-battery-revolution-in-motion [Accessed 30 August 2019].

Conder, J.M., Vaulot, C., Marino, C., Villevieille, C., and Ghimbeu, C.M. (2019). Chitin and chitosan-Structurally-related precursors of dissimilar hard carbons for Na-ion battery. ACS Appl. Energy Mater., 2, 4841-4852.

Dahbi, M., Kiso, M., Kubota, K., Horiba, T., Chafik, T., Hida, K., Matsuyama, T., and Komaba, S. (2017). Synthesis of hard carbon from argan shells for Na-ion batteries. Journal of Materials Chemistry A, 5(20), 9917-9928.

Ding, J., Wang, H., Li, Z., Kohandehghan, A., Cui, K., Xu, Z., Zahiri, B., Tan, X., Lotfabad, E.M., Olsen, B.C., and Mitlin, D. (2013a). Carbon nanosheet frameworks derived from peat moss as high performance sodium ion battery anodes. ACS Nano, 7(12), 1100411015.

Dahn, J.R., Xing, W., Gao, Y. (1997). The "falling cards model" for the structure of microporous carbons. Carbon, 35(6), 825-830.

Dou, X., Geng, C., Buchholz, D., and Passerini, S. (2018). Research update: Hard carbon with closed pores from pectin-free apple pomace waste for Na-ion batteries. APL Materials, 6(4), 047501.

Dou, X., Hasa, I., Hekmatfar, M., Diemant, T., Behm, R.J., Buchholz, D., and Passerini, S. (2017). Pectin, hemicellulose, or lignin? Impact of the biowaste source on the performance of hard carbons for sodium-ion batteries. ChemSusChem, 10(12), 26682676.

Dou, X., Hasa, I., Saurel, D., Vaalma, C., Wu, L., Buchholz, D., Bresser, D., Komaba, S., and Passerini, S. (2019). Hard carbons for sodium-ion batteries: Structure, analysis, sustainability, and electrochemistry. Mater. Today. 23, 2019, 87-104.

En ligneGreen Car Congress. (n.d.). Faradion demonstrates proof-of-concept sodium-ion electric bike. [Online]. Available at: https://www.greencarcongress.com/2015/05/20150515faradion.html [Accessed 1 September 2019].

EUR-Lex. (n.d.). Directive 2009/28/EC of the European Parliament and of the Council of 23 April 2009 on the promotion of the use of energy from renewable sources and amending and subsequently repealing Directives 2001/77/EC and 2003/30/EC (Text with EEA relevance). [Online]. Available at: http://eur-lex.europa.eu/eli/dir/2009/28/oj [Accessed 29 January 2018].

Faradion. (n.d.). Strong performance. [Online]. Available at: https://www.faradion.co.uk/ technology-benefits/strong-performancel [Accessed 1 September 2019].

Ferreri, A.C. and Robertson, J. (2000). Interpretation of Raman spectra of disordered and amorphous carbon. Physical Review, 61, 14095-14107.

Franklin, R. E. (1951). Crystallite Growth in Graphitizing and Non-Graphitizing Carbons. Proc. R. Soc. A Math. Phys. Eng. Sci. 209, 196-218.

Gao, X., An, Y., Zhang, W., Yu, M., Ci, L., and Feng, J. (2018). Self-supporting soft carbon fibers as binder-free and flexible anodes for high-performance sodium-ion batteries. Materials Technology, 33(12). https://www.tandfonline.com/doi/abs/10.1080/10667857. 2018.1509525.

Górka, J., Vix-Guterl, C., and Matei Ghimbeu, C. (2016). Recent progress in design of biomass-derived hard carbons for sodium ion batteries. C, 2(4), 24.

Gotoh, K., Ishikawa, T., Shimadzu, S., Yabuuchi, N., Komaba, S., Takeda, K., Goto, A., Deguchi, K., Ohki, S., Hashi, K., Shimizu, T., and Ishida, H. (2013). NMR study for 
electrochemically inserted Na in hard carbon electrode of sodium ion battery. Journal of Power Sources, 225(Supplement C), 137-140.

Haas, T.J., Nimlos, M.R., and Donohoe, B.S. (2009). Real-time and post-reaction microscopic structural analysis of biomass undergoing pyrolysis. Energy \& Fuels, 23(7), 3810 3817.

Harris, P.J.F. and Tsang, S.C. (1997). High-resolution electron microscopy studies of nongraphitizing carbons. Philosophical Magazine A, 76(3), 667-677.

Hasa, I., Hassoun, J., and Passerini, S. (2017). Nanostructured Na-ion and Li-ion anodes for battery application: A comparative overview. Nano Research, 10, 1-28.

Hasegawa, G., Kanamori, K., Kannari, N., Ozaki, J., Nakanishi, K., and Abe, T. (2015). Hard carbon anodes for Na-ion batteries: Toward a practical use. ChemElectroChem, 2(12), 1917-1920.

HiNa Battery Technology Co., Ltd. (n.d.). Na-ion battery-Sodium ion battery. [Online]. Available at: http://www.hinabattery.com/en/index.php?catid=12 [Accessed 1 September 2019].

Hong, Z., Zhen, Y., Ruan, Y., Kang, M., Zhou, K., Zhang, J.-M., Huang, Z., and Wei, M. (2018). Rational design and general synthesis of S-doped hard carbon with tunable doping sites toward excellent Na-ion storage performance. Advanced Materials, 30(29), 1802035.

Inagaki, M. and Kang, F. (2016). Materials Science and Engineering of Carbon:

Characterization. Butterworth-Heinemann, Oxford, UK, and Cambridge, USA.

Industrie-techno. (2018). Trottinette électrique: la batterie sodium-ion a sa première application.[Online]. 2018. Available at: /article/trottinette-electrique-la-batteriesodium-ion-a-sapremiere-application.53164 [Accessed 1 September 2019].

Irisarri, E., Amini, N., Tennison, S., Ghimbeu, C.M., Gorka, J., Vix-Guterl, C., Ponrouch, A., and Palacin, M.R. (2018). Optimization of large scale produced hard carbon performance in Na-ion batteries: Effect of precursor, temperature and processing conditions. Journal of The Electrochemical Society, 165(16), A4058-A4066.

Irisarri, E., Ponrouch, A., and Palacin, M.R. (2015). Review-hard carbon negative electrode materials for sodium-ion batteries. Journal of The Electrochemical Society, 162(14), A2476-A2482.

Izanzar, I., Dahbi, M., Kiso, M., Doubaji, S., Komaba, S., and Saadoune, I. (2018). Hard carbons issued from date palm as efficient anode materials for sodium-ion batteries. Carbon, 137, 165-173.

Jiang, Q., Zhang, Z., Yin, S., Guo, Z., Wang, S., and Feng, C. (2016). Biomass carbon micro/nano-structures derived from ramie fibers and corncobs as anode materials for lithium-ion and sodium-ion batteries. Applied Surface Science, 379, 73-82.

Jin, J., Yu, B., Shi, Z., Wang, C., and Chong, C. (2014). Lignin-based electrospun carbon nanofibrous webs as free-standing and binder-free electrodes for sodium ion batteries. Journal of Power Sources, 272, 800-807.

Kim, D., Lee, E., Slater, M., Lu, W., Rood, S., and Johnson, C.S. (2012). Layered $\mathrm{Na}[\mathrm{Nil} / 3 \mathrm{Fe}$ 1/3Mn1/3]O2 cathodes for Na-ion battery application. Electrochemistry Communications, 18, 66-69.

Kim, K., Lim, D.G., Han, C.W., Osswald, S., Ortalan, V., Youngblood, J.P., and Pol, V.G. (2017). Tailored carbon anodes derived from biomass for sodium-ion storage. ACS Sustainable Chemistry \& Engineering, 5(10), 8720-8728.

Kipling, J.J., Sherwood, J.N., Shooter, P.V., and Thompson, N.R. (1964). The pore structure and surface area of high-temperature polymer carbons. Carbon, 1(3), 321-328.

Komaba, S., Murata, W., Ishikawa, T., Yabuuchi, N., Ozeki, T., Nakayama, T., Ogata, A., Gotoh, K., and Fujiwara, K. (2011). Electrochemical Na insertion and solid electrolyte 
interphase for hard-carbon electrodes and application to Na-ion batteries. Advanced Functional Materials, 21(20), 3859-3867.

Komaba, S., Yamamoto, H., Kubota, K., Muratsubaki, S., Dahbi, M., and Manivannan, A. (2017). (Invited) Hard carbons made from cellulose for $\mathrm{Na}$ - and $\mathrm{K}$-ion batteries. Meeting Abstracts, MA2017-01(1), 44.

Ku, H., Trade, M., Nixon, R., and Wong, P. (2010). Flexural properties of phenolic resin reinforced with glass powder: Preliminary results. Journal of Applied Polymer Science, 116(1), 347-354.

Kumar, M., Olajire Oyedun, A., and Kumar, A. (2018). A review on the current status of various hydrothermal technologies on biomass feedstock. Renewable and Sustainable Energy Reviews, 81, 1742-1770.

Li, H., Shen, F., Luo, W., Dai, J., Han, X., Chen, Y., Yao, Y., Zhu, H., Fu, K., Hitz, E., and $H u, L .(2016 a)$. Carbonized-leaf membrane with anisotropic surfaces for sodium-ion battery. ACS Applied Materials \& Interfaces, 8(3), 2204-2210.

Li, R., Huang, J., Xu, Z., Qi, H., Cao, L., Liu, Y., Li, W., and Li, J. (2018). Controlling the thickness of disordered turbostratic nanodomains in hard carbon with enhanced sodium storage performance. Energy Technology, 6(6), 1080-1087.

Li, W., Huang, J., Feng, L., Cao, L., Ren, Y., Li, R., Xu, Z., Li, J., and Yao, C. (2017a). Controlled synthesis of macroscopic three-dimensional hollow reticulate hard carbon as long-life anode materials for Na-ion batteries. Journal of Alloys and Compounds, 716, 210-219.

Li, Y., Hu, Y.-S., Li, H., Chen, L., and Huang, X. (2015). A superior low-cost amorphous carbon anode made from pitch and lignin for sodium-ion batteries. Journal of Materials Chemistry A, 4(1), 96-104.

Li, Y., Hu, Y.-S., Titirici, M.-M., Chen, L., and Huang, X. (2016b). Hard carbon microtubes made from renewable cotton as high-performance anode material for sodium-ion batteries. Advanced Energy Materials, 6(18), 1600659.

Li, Y., Mu, L., Hu, Y.-S., Li, H., Chen, L., and Huang, X. (2016c). Pitch-derived amorphous carbon as high performance anode for sodium-ion batteries. Energy Storage Materials, 2, 139-145.

Li, Y., Paranthaman, M.P., Akato, K., Naskar, A.K., Levine, A.M., Lee, R.J., Kim, S.-O., Zhang, J., Dai, S., and Manthiram, A. (2016d). Tire-derived carbon composite anodes for sodium-ion batteries. Journal of Power Sources, 316, 232-238.

Li, Y., Xu, S., Wu, X., Yu, J., Wang, Y., Hu, Y.-S., Li, H., Chen, L., and Huang, X. (2014). Amorphous monodispersed hard carbon micro-spherules derived from biomass as a high performance negative electrode material for sodium-ion batteries. Journal of Materials Chemistry A, 3(1), 71-77.

Li, Z., Bommier, C., Chong, Z.S., Jian, Z., Surta, T.W., Wang, X., Xing, Z., Neuefeind, J.C., Stickle, W.F., Dolgos, M., Greaney, P.A., and Ji, X. (2017). Mechanism of Na-ion storage in hard carbon anodes revealed by heteroatom doping. Advanced Energy Materials, 7(18), 1602894.

Liu, Y., Merinov, B.V., and Goddard, W.A. (2016). Origin of low sodium capacity in graphite and generally weak substrate binding of $\mathrm{Na}$ and $\mathrm{Mg}$ among alkali and alkaline earth metals. Proceedings of the National Academy of Sciences, 113(14), 3735-3739.

Liu, Y., Sun, Y., and Huang, G. (2018). Preparation and antioxidant activities of important traditional plant polysaccharides. International Journal of Biological Macromolecules, 111, 780-786.

Lotfabad, E.M., Ding, J., Cui, K., Kohandehghan, A., Kalisvaart, W.P., Hazelton, M., and Mitlin, D. (2014a). High-density sodium and lithium ion battery anodes from banana peels. ACS Nano, 8(7), 7115-7129. 
Luo, W., Bommier, C., Jian, Z., Li, X., Carter, R., Vail, S., Lu, Y., Lee, J.-J., and Ji, X. (2015). Low-surface-area hard carbon anode for na-ion batteries via graphene oxide as a dehydration agent. ACS Applied Materials \& Interfaces, 7(4), 2626-2631.

Luo, W., Schardt, J., Bommier, C., Wang, B., Razink, J., Simonsen, J., and Ji, X. (2013). Carbon nanofibers derived from cellulose nanofibers as a long-life anode material for rechargeable sodium-ion batteries. Journal of Materials Chemistry A, 1(36), 1066210666.

Lv, W., Wen, F., Xiang, J., Zhao, J., Li, L., Wang, L., Liu, Z., and Tian, Y. (2015). Peanut shell derived hard carbon as ultralong cycling anodes for lithium and sodium batteries. Electrochimica Acta, 176, 533-541.

Matei Ghimbeu, C., Górka, J., Simone, V., Simonin, L., Martinet, S., and Vix-Guterl, C. (2018). Insights on the Na+ ion storage mechanism in hard carbon: Discrimination between the porosity, surface functional groups and defects. Nano Energy, 44, 327-335.

Matei Ghimbeu, C., Zhang, B., Martinez de Yuso, A., Rety, B., and Tarascon, J.-M. (2019) Valorizing low cost and renewable lignin as hard carbon for Na-ion batteries: Impact of lignin grade. Carbon, 153, 634-647.

Meents, M.J., Watanabe, Y., and Samuels, A.L. (2018). The cell biology of secondary cell wall biosynthesis. Annals of Botany, 121(6), 1107-1125.

Meng, X., Savage, P.E., and Deng, D. (2015). Trash to treasure: From harmful algal blooms to high-performance electrodes for sodium-ion batteries. Environmental Science \& Technology, 49(20), 12543-12550.

Ministère des Armées. (2017). Des batteries innovantes au service des armées. [Online]. Available at: https://www.defense.gouv.fr/english/actualites/articles/video-desbatteriesinnovantes-au-service-des-armees [Accessed 1 September 2019].

Narasimman, $R$. and Prabhakaran, K. (2013). Preparation of carbon foams with enhanced oxidation resistance by foaming molten sucrose using a boric acid blowing agent. Carbon, 55, 305-312.

Novák, P., Ufheil, J., Buqa, H., Krumeich, F., Spahr, M.E., Goers, D., Wilhelm, H., Dentzer, J., Gadiou, R., and Vix-Guterl, C. (2007). The importance of the active surface area of graphite materials in the first lithium intercalation. Journal of Power Sources, 174(2), 1082-1085.

Oberlin, A. and Terriere, G. (1975). Graphitization studies of anthracites by high resolution electron microscopy. Carbon, 13(5), 367-376.

Ponrouch, A. and Palacín, M.R. (2015). On the high and low temperature performances of Na-ion battery materials: Hard carbon as a case study. Electrochemistry Communications, 54, 51-54.

Ponrouch, A., Dedryvère, R., Monti, D., Demet, A.E., Mba, J.M.A., Croguennec, L., Masquelier, C., Johansson, P., and Palacín, M.R. (2013). Towards high energy density sodium ion batteries through electrolyte optimization. Energy \& Environmental Science 6(8), 2361-2369.

Qin, X., Lu, Y., Xiao, H., Wen, Y., and Yu, T. (2012). A comparison of the effect of graphitization on microstructures and properties of polyacrylonitrile and mesophase pitchbased carbon fibers. Carbon, 50(12), 4459-4469.

Qiu, S., Xiao, L., Sushko, M.L., Han, K.S., Shao, Y., Yan, M., Liang, X., Mai, L., Feng, J., Cao, Y., Ai, X., Yang, H., and Liu, J. (2017). Manipulating adsorption-insertion mechanisms in nanostructured carbon materials for high-efficiency sodium ion storage. Advanced Energy Materials, 7(17), 1700403.

Rodriguez Correa, C., Hehr, T., Voglhuber-Slavinsky, A., Rauscher, Y., and Kruse, A. (2019). Pyrolysis vs. hydrothermal carbonization: Understanding the effect of biomass structural components and inorganic compounds on the char properties. Journal of 
Analytical and Applied Pyrolysis, 140, 137-147.

Rodríguez-Reinoso, F. and Molina-Sabio, M. (1992). Activated carbons from lignocellulosic materials by chemical and/or physical activation: An overview. Carbon, 30(7), 11111118.

Saavedra Rios, C. del M., Simone, V., Simonin, L., Martinet, S., and Dupont, C. (2018). Biochars from various biomass types as precursors for hard carbon anodes in sodiumion batteries. Biomass and Bioenergy, 117, 32-37.

Saurel, D., Orayech, B., Xiao, B., Carriazo, D., Li, X., and Rojo, T. (2018). From charge storage mechanism to performance: A roadmap toward high specific energy sodiumion batteries through carbon anode optimization. Advanced Energy Materials, 8(17), 1703268.

Shen, F., Zhu, H., Luo, W., Wan, J., Zhou, L., Dai, J., Zhao, B., Han, X., Fu, K., and Hu, L. (2015). Chemically crushed wood cellulose fiber towards high-performance sodium-ion batteries. ACS Applied Materials \& Interfaces, 7(41), 23291-23296.

Simone, V. (2016). Développement d'accumulateurs sodium-ion. PhD thesis, Université Grenoble Alpes, Grenoble.

Simone, V., Boulineau, A., de Geyer, A., Rouchon, D., Simonin, L., and Martinet, S. (2016). Hard carbon derived from cellulose as anode for sodium ion batteries: Dependence of electrochemical properties on structure. Journal of Energy Chemistry, 25(5), 761-768.

Spahr, M.E., Buqa, H., Würsig, A., Goers, D., Hardwick, L., Novák, P., Krumeich, F., Dentzer, J., and Vix-Guterl, C. (2006). Surface reactivity of graphite materials and their surface passivation during the first electrochemical lithium insertion. Journal of Power Sources, 153(2), 300-311.

Stevens, D.A. and Dahn, J.R. (2000). High capacity anode materials for rechargeable sodium-ion batteries. Journal of the Electrochemical Society, 147(4), 1271-1273.

Stevens, D.A. and Dahn, J.R. (2001). The mechanisms of lithium and sodium insertion in carbon materials. Journal of the Electrochemical Society, 148(8), A803-A811.

Talekar, S., Patti, A.F., Vijayraghavan, R., and Arora, A. (2018). Complete utilization of waste pomegranate peels to produce a hydrocolloid, punicalagin rich phenolics, and a hard carbon electrode. ACS Sustainable Chemistry \& Engineering, 6(12), 1636316374.

Tang, K., Fu, L., White, R.J., Yu, L., Titirici, M.-M., Antonietti, M., and Maier, J. (2012). Hollow carbon nanospheres with superior rate capability for sodium-based batteries. Advanced Energy Materials, 2(7), 873-877.

Thomas, P. and Billaud, D. (2002). Electrochemical insertion of sodium into hard carbons. Electrochimica Acta, 47(20), 3303-3307.

Tsai, P., Chung, S.-C., Lin, S., and Yamada, A. (2015). Ab initio study of sodium intercalation into disordered carbon. Journal of Materials Chemistry A, 3(18), 97639768.

Väli, R., Jänes, A., and Lust, E. (2017b). Alkali-metal insertion processes on nanospheric hard carbon electrodes: An electrochemical impedance spectroscopy study. Journal of the Electrochemical Society, 164(11), E3429-E3437.

Väli, R., Jänes, A., Thomberg, T., and Lust, E. (2016). D-glucose derived nanospheric hard carbon electrodes for room-temperature sodium-ion batteries. Journal of the Electrochemical Society, 163(8), A1619-A1626.

Väli, R., Jänes, A., Thomberg, T., and Lust, E. (2017a). Synthesis and characterization of $d$-glucosederived nanospheric hard carbon negative electrodes for lithium-and sodiumion batteries. Electrochimica Acta, 253, 536-544.

Vassilev, S.V., Baxter, D., Andersen, L.K., Vassileva, C.G., and Morgan, T.J. (2012). An overview of the organic and inorganic phase composition of biomass. Fuel, 94, 1-33. 
Wang, H., Shi, Z., Jin, J., Chong, C., and Wang, C. (2015). Properties and sodium insertion behavior of phenolic resin-based hard carbon microspheres obtained by a hydrothermal method. Journal of Electroanalytical Chemistry, 755, 87-91.

Wang, H., Yu, W., Shi, J., Mao, N., Chen, S., and Liu, W. (2016a). Biomass derived hierarchical porous carbons as high-performance anodes for sodium-ion batteries. Electrochimica Acta, 188(Supplement C), 103-110.

Wang, K., Jin, Y., Sun, S., Huang, Y., Peng, J., Luo, J., Zhang, Q., Qiu, Y., Fang, C., and Han, J. (2017a). Low-cost and high-performance hard carbon anode materials for sodium ion batteries. ACS Omega, 2(4), 1687-1695.

Wang, Q., Zhao, C., Lu, Y., Li, Y., Zheng, Y., Qi, Y., Rong, X., Jiang, L., Qi, X., Shao, Y., Pan, D., Li, B., Hu, Y.-S., and Chen, L. (2017). Advanced nanostructured anode materials for sodium-ion batteries. Small, 13(42), 1701835.

Wang, Q., Zhu, X., Liu, Y., Fang, Y., Zhou, X., and Bao, J. (2018a). Rice husk-derived hard carbons as high-performance anode materials for sodium-ion batteries. Carbon, 127, 658-666.

Wang, S., Xia, L., Yu, L., Zhang, L., Wang, H., and Lou, X.W. (2016b). Free-standing nitrogen-doped carbon nanofiber films: Integrated electrodes for sodium-ion batteries with ultralong cycle life and superior rate capability. Advanced Energy Materials, 6(7), 1502217.

Wang, T., Zhai, Y., Zhu, Y., Li, C., and Zeng, G. (2018b). A review of the hydrothermal carbonization of biomass waste for hydrochar formation: Process conditions, fundamentals, and physicochemical properties. Renewable and Sustainable Energy Reviews, 90, 223-247.

Warren, B.E. (1934). X-ray diffraction study of carbon black. The Journal of Chemical Physics, 2(9), 551-555.

Warren, B.E. (1941). X-ray diffraction in random layer lattices. Physical Review, 59(9), 693698.

Wu, L., Buchholz, D., Vaalma, C., Giffin, G.A., and Passerini, S. (2016). Apple-biowastederived hard carbon as a powerful anode material for Na-ion batteries. ChemElectroChem, 3(2), 292-298.

Xiang, J., Lv, W., Mu, C., Zhao, J., and Wang, B. (2017). Activated hard carbon from orange peel for lithium/sodium ion battery anode with long cycle life. Journal of Alloys and Compounds, 701(Supplement C), 870-874.

Xu, S.-D., Zhao, Y., Liu, S., Ren, X., Chen, L., Shi, W., Wang, X., and Zhang, D. (2018). Curly hard carbon derived from pistachio shells as high-performance anode materials for sodium-ion batteries. Journal of Materials Science, 53(17), 12334-12351.

Yamamoto, H., Muratsubaki, S., Kubota, K., Fukunishi, M., Watanabe, H., Kim, J., and Komaba, S. (2018). Synthesizing higher-capacity hard-carbons from cellulose for $\mathrm{Na-}$ and $K$-ion batteries. Journal of Materials Chemistry A, 6(35), 16844-16848.

Ye, J., Zang, J., Tian, Z., Zheng, M., and Dong, Q. (2016). Sulfur and nitrogen co-doped hollow carbon spheres for sodium-ion batteries with superior cyclic and rate performance. Journal of Materials Chemistry A, 4(34), 13223-13227.

Yu, C., Hou, H., Liu, X., Yao, Y., Liao, Q., Dai, Z., and Li, D. (2018a). Old-loofah-derived hard carbon for long cyclicity anode in sodium ion battery. International Journal of Hydrogen Energy, 43(6), 3253-3260.

$Y u, Y .$, Shen, M., Song, Q., and Xie, J. (2018b). Biological activities and pharmaceutical applications of polysaccharide from natural resources: A review. Carbohydrate Polymers, 183, 91-101.

Zeng, L., Li, W., Cheng, J., Wang, J., Liu, X., and Yu, Y. (2014). N-doped porous hollow carbon nanofibers fabricated using electrospun polymer templates and their sodium 
storage properties. RSC Advances, 4(33), 16920-16927.

Zhang, B., Ghimbeu, C.M., Laberty, C., Vix-Guterl, C., and Tarascon, J.-M. (2016).

Correlation between microstructure and Na storage behavior in hard carbon. Advanced Energy Materials, 6(1), 1501588.

Zhang, F., Yao, Y., Wan, J., Henderson, D., Zhang, X., and Hu, L. (2017a). High temperature carbonized grass as a high performance sodium ion battery anode. ACS Applied Materials \& Interfaces, 9(1), 391-397.

Zhang, H., Ming, H., Zhang, W., Cao, G., and Yang, Y. (2017b). Coupled carbonization strategy toward advanced hard carbon for high-energy sodium-ion battery. ACS Applied Materials \& Interfaces, 9(28), 23766-23774.

Zhang, N., Liu, Q., Chen, W., Wan, M., Li, X., Wang, L., Xue, L., and Zhang, W. (2018a). High capacity hard carbon derived from lotus stem as anode for sodium ion batteries. Journal of Power Sources, 378, 331-337.

Zhang, S., Li, Y., and Li, M. (2018b). Porous hard carbon derived from walnut shell as an anode material for sodium-ion batteries. JOM, 70(8), 1387-1391.

Zhang, T., Mao, J., Liu, X., Xuan, M., Bi, K., Zhang, X.L., Hu, J., Fan, J., Chen, S., and Shao, G. (2017c). Pinecone biomass-derived hard carbon anodes for high-performance sodium-ion batteries. RSC Advances, 7(66), 41504-41511.

Zhang, Y., Li, X., Dong, P., Wu, G., Xiao, J., Zeng, X., Zhang, Y, and Sun, X. (2018c).

Honeycomb-like hard carbon derived from pine pollen as high-performance anode material for sodium-ion batteries. ACS Applied Materials \& Interfaces, 10(49), 4279642803.

Zhang, Z., Brydson, R., Aslam, Z., Reddy, S., Brown, A., Westwood, A., and Rand, B. (2011). Investigating the structure of non-graphitising carbons using electron energy loss spectroscopy in the transmission electron microscope. Carbon, 49(15), 5049-5063.

Zhao, P.-Y., Yu, B.-J., Sun, S., Guo, Y., Chang, Z.-Z., Li, Q., and Wang, C.-Y. (2017).

High-performance anode of sodium ion battery from polyacrylonitrile/humic acid composite electrospun carbon fibers. Electrochimica Acta, 232, 348-356.

Zhu, H., Shen, F., Luo, W., Zhu, S., Zhao, M., Natarajan, B., Dai, J., Zhou, L., Ji, X., Yassar, R.S., Li, T., and Hu, L. (2017a). Low temperature carbonization of cellulose nanocrystals for high performance carbon anode of sodium-ion batteries. Nano Energy, 33, 37-44.

Zhu, X., Jiang, X., Liu, X., Xiao, L., and Cao, Y. (2017b). A green route to synthesize lowcost and high-performance hard carbon as promising sodium-ion battery anodes from sorghum stalk waste. Green Energy \& Environment, 2(3), 310-315.

Zhu, Y., Chen, M., Li, Q., Yuan, C., and Wang, C. (2017c). High-yield humic acid-based hard carbons as promising anode materials for sodium-ion batteries. Carbon, 123(Supplement C), 727-734.

Zhu, Y., Chen, M., Li, Q., Yuan, C., and Wang, C. (2018). A porous biomass-derived anode for high-performance sodium-ion batteries. Carbon, 129, 695-701. 